\title{
MESHFREE MODELING AND HOMOGENIZATION OF 3D ORTHOGONAL WOVEN COMPOSITES
}

\author{
L. Y. Li \\ Department of Aeronautics, Imperial College, London SW7 2AZ, UK \\ P. H. Wen
}

School of Engineering and Materials Science, Queen Mary University of London, London E1 4NS, UK

M. H. Aliabadi

Department of Aeronautics, Imperial College, London SW7 2AZ, UK

\begin{abstract}
In this paper, evaluation of 3D orthogonal woven fabric composite elastic moduli is achieved by applying Meshfree methods on the micromechanical model of the woven composites. A new, realistic and smooth fabric unit cell model of 3D orthogonal woven composite is presented. As an alternative to Finite Element Method, Meshfree Methods show a notable advantage, which is the simplicity in meshing while modelling the matrix and different yarns. Radial basis function and moving kriging interpolation are used for the shape function constructions. The Galerkin method is employed in formulating the discretized system equations. The numerical results are compared with the Finite Element and the experimental results.
\end{abstract}

Keywords: Meshfree method; 3D orthogonal woven fabric composites; elastic moduli; Galerkin; radial basis; moving kriging 


\title{
MESHFREE MODELING AND HOMOGENIZATION OF 3D ORTHOGONAL WOVEN COMPOSITES
}

\author{
L. Y. Li \\ Department of Aeronautics, Imperial College, London SW7 2AZ, UK \\ P. H. Wen \\ School of Engineering and Materials Science, Queen Mary University of London, London E1 4NS, UK \\ M. H. Aliabadi \\ Department of Aeronautics, Imperial College, London SW7 2AZ, UK

\begin{abstract}
In this paper, evaluation of 3D orthogonal woven fabric composite elastic moduli is achieved by applying Meshfree methods on the micromechanical model of the woven composites. A new, realistic and smooth fabric unit cell model of 3D orthogonal woven composite is presented. As an alternative to Finite Element Method, Meshfree Methods show a notable advantage, which is the simplicity in meshing while modelling the matrix and different yarns. Radial basis function and moving kriging interpolation are used for the shape function constructions. The Galerkin method is employed in formulating the discretized system equations. The numerical results are compared with the Finite Element and the experimental results.
\end{abstract}

Keywords: Meshfree method; 3D orthogonal woven fabric composites; elastic moduli; Galerkin; radial basis; moving kriging

\section{Introduction}

Composites with their anisotropic nature carry advantageous properties such as high specific stiffness, specific strength, toughness, etc. Woven fabric composites are being considered as more competitive than unidirectional composites as their ability to provide dramatically improved fracture toughness, better impact resistance, reduced notch sensitivity, easier handling and fabrication, etc. However, due to the very complex fibre architectures, there are certain difficulties such as inaccurate fabric geometry modelling and low computational efficiency, while analysing their behaviour. Woven fabrics can basically be categorized into 2D woven fabrics, for instance, plain weave, twill weave and satin weave textile, and 3D woven fabrics, for example, 3D orthogonal, 3D through-thickness interlock and 3D layer to layer interlock woven fabrics. In 2D woven fabrics, yarns usually undergo low-angle undulation to obtain the maximum composite stiffness and strength. Traditionally, for thick composite sections, layers of 2D woven fabrics are laid on top of each other to achieve the desired thickness and/or fill the mold gap. Therefore, to achieve superior properties in the transverse or through thickness direction, the use of 3D preforms is required. In 3D fabrics involving multi-axis reinforcements, the pattern of yarn interlacing can be more complicated.

Earlier models for the analysis of 2D woven fabric composites developed by Ishikawa and Chou [1] include the 'mosaic model' for predicting the elastic properties of fabric composites, the 'fibre undulation model' for plain woven fabric, and the 'bridging model' for satin composites. Naik and Shembekar [2] developed two-dimensional woven composite models for the elastic analysis of plain weave fabric lamina. Karayaka and Kurath [3] proposed a micromechanistic deformation model capable of representing both plain weave and satin 
weave composite layers. A micromechanical composite material model for plain woven fabric with nonlinear stress-strain relations was developed and implemented in ABAQUS for nonlinear finite element structural analysis by Tabiei and Jiang [4]. Later Tanov and Tabiei [5] presented two micromechanical models for the analysis of plain weave fabric composites. Both models utilize the representative volume cell approach. More recently, Lua [6] developed new four-cell micromechanics model which is for an unbalanced weave subjected to a thermal-mechanical loading. Wen and Aliabadi [7] developed a meshfree micromechanical material model for evaluation of plain woven fabric composite elastic moduli, which does not require formal element mesh to model the matrix and yarns.

By comparison, there are less publications addressed 3D woven fabric composites due to the even more complex and very diverse three-dimensional fiber architectures. Among different types of 3D woven fabrics, the orthogonal woven composites have relatively simple weaving structure as they are similar with laminates. Therefore most of the comparable research results, both experimental and finite element, are achieved for 3D orthogonal woven composites. Tan, Tong and Steven [8] developed one of the earliest unit cell models of 3D orthogonal woven composites based on so-called $X$ model, $Y$ model, $Z$ model. More recently, a simplified unit cell model for 3D orthogonal woven composites was used to investigate the thermo-elastic performance of this fabric architecture [9]. However it can't describe the complete structure of the weave pattern, especially the z-yarn, therefore, in Lee's research [10], a large-scale FEA based on the direct numerical simulation was applied to investigate the material characterization. The unit cell structure in Lee's research considered the interlacing of Z-yarn and filler yarns. One of the most realistic unit cell models of 3D orthogonal woven composites was presented by Bogdanovich [11]. It considered the non-vertical shape of Zyarn which was generated according to direct measurements of the produced fabric and composites. For other interesting work on woven composites, readers should consult [12-17].

During the last decades, meshfree methods, as an alternative to Finite Element Method (FEM), have shown a promising potential and has found applications on various problems. Among different kinds of meshfree methods proposed so far, see[18-26], Element free Galerkin (EFG) [21] and Meshless local Petrov-Galerkin (MLPG) [25] have gained the much attention and both used Moving least square (MLS) approximation as the shape function construction. More recently, Liu and Gu [26] introduced a point interpolation method which uses Radial basis (RB) function to construct the shape function. Wen and Aliabadi [27-30] applied Radial basis function on analysis of elastodynamic, functionally gradient materials and fracture mechanics problems. Lei Gu [31] proposed a new formulation of EFG through the moving kriging (MK) interpolation in order to eliminate the shortcoming that EFG shape function does not satisfy the Kronecker delta property. The work of Wen and Aliabadi [7] is the first application of meshfree method on woven composites and shows that the meshfree approach is particularly efficient in comparison with the finite element method. The results obtained were found to be in good agreement with analytical and finite element solutions.

In this paper, RB functions and MK interpolation are both applied on the meshfree approach for evaluation of $3 \mathrm{D}$ orthogonal woven fabric composite elastic moduli. A new smooth fabric unit cell model of 3D orthogonal woven composites is presented and applied to the meshfree approach. Comparisons are made with Finite Element and experimental results.

\section{Shape Function Constructions for Meshfree Method}




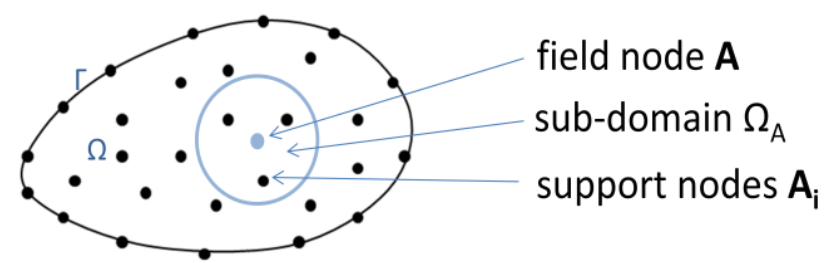

Figure 1 Sketch of domains and boundaries of 2D cases for Meshfree Method

\section{Radial Basis Function Interpolation}

Consider a problem domain $\Omega$ which is represented by a set of nodes in the domain $\Omega$ and on the boundary $\Gamma$, as shown in Figure 1. Let $u(A)$ be the function of the field variable defined in the domain $\Omega$. The approximation of displacement $\mathrm{u}$ at point $\mathbf{A}\left(\mathrm{x}_{\mathrm{A}}, \mathrm{y}_{\mathrm{A}}, \mathrm{z}_{\mathrm{A}}\right)$ can be expressed by

$$
\mathrm{u}(\mathbf{A})=\sum_{\mathrm{i}=1}^{\mathrm{n}} \mathrm{R}_{\mathrm{i}}(\mathbf{A}) \mathrm{a}_{\mathrm{i}}=\mathbf{R}^{\mathrm{T}}(\mathbf{A}) \mathbf{a}(\mathbf{A})
$$

where $n$ is the number of nodes in the sub-domain $\Omega_{A}$ of point $\mathbf{A}$, and $\left\{a_{i}\right\}_{i=1}^{n}$ are the unknown coefficients to be determined for the basis function $R_{i}(A)$ corresponding to point $A$. $R_{i}(\mathbf{A})$ is a radial basis function related to the distance between point $\mathbf{A}$ and $\mathbf{A}_{\mathrm{i}}$. A classical form of radial basis functions is the multiquadric (MQ) basis proposed by Hardy [32]. For 3D cases, it can be written as

$$
\mathrm{R}_{\mathrm{i}}(\mathbf{A})=\sqrt{\mathrm{c}^{2}+\mathrm{a}_{\mathrm{x}}^{2}\left(\mathrm{x}_{\mathrm{A}}-\mathrm{x}_{\mathrm{i}}\right)^{2}+\mathrm{a}_{\mathrm{y}}^{2}\left(\mathrm{y}_{\mathrm{A}}-\mathrm{y}_{\mathrm{i}}\right)^{2}+\mathrm{a}_{\mathrm{z}}^{2}\left(\mathrm{z}_{\mathrm{A}}-\mathrm{z}_{\mathrm{i}}\right)^{2}}
$$

where $\mathrm{c}$ is a free parameter (is chosen to unit in this paper) and $\mathrm{a}_{\mathrm{x}}, \mathrm{a}_{\mathrm{y}}$ and $\mathrm{a}_{\mathrm{z}}$ are scale factors.

$$
\begin{gathered}
\mathbf{R}^{\mathrm{T}}(\mathbf{A})=\left\{\mathrm{R}_{1}(\mathbf{A}), \mathrm{R}_{2}(\mathbf{A}), \ldots, \mathrm{R}_{\mathrm{n}}(\mathbf{A})\right\} \\
\mathbf{a}(\mathbf{A})=\left\{\mathrm{a}_{1}, \mathrm{a}_{2}, \ldots, \mathrm{a}_{\mathrm{n}}\right\}
\end{gathered}
$$

From the interpolation equation (1) for the RB functions, a linear system for the unknown coefficients $\mathbf{a}$ is obtained:

where

$$
\mathbf{u}=\mathbf{R}_{\mathbf{0}} \mathbf{a}
$$

The matrix $\mathbf{R}_{0}$ is assured to be invertible since the radial basis(RB) functions are positive definite. Therefore

$$
\mathbf{a}=\mathbf{R}_{0}^{-1} \mathbf{u}
$$

Equation (1) can be rewritten as

$$
\mathrm{u}(\mathbf{A})=\mathbf{R}^{\mathrm{T}}(\mathbf{A}) \mathbf{R}_{0}{ }^{-1} \mathbf{u}=\boldsymbol{\Phi}(\mathbf{A}) \mathbf{u}=\sum_{\mathrm{i}=1}^{\mathrm{n}} \phi_{\mathrm{i}}(\mathbf{A}) \mathrm{u}_{\mathrm{i}}
$$


where the matrix of shape functions $\boldsymbol{\Phi}(\mathbf{A})$ is defined by:

$$
\boldsymbol{\Phi}(\mathbf{A})=\mathbf{R}^{\mathrm{T}}(\mathbf{A}) \mathbf{R}_{0}^{-1}
$$

or in the matrix form:

$$
\boldsymbol{\Phi}(\mathbf{A})=\left[\phi_{1}(\mathbf{A}), \phi_{2}(\mathbf{A}), \ldots \phi_{\mathrm{i}}(\mathbf{A}), \ldots, \phi_{\mathrm{n}}(\mathbf{A})\right]
$$

Since the term $\mathbf{R}_{0}^{-1}$ contains no variable, the derivatives of shape functions against $\mathrm{x}_{\mathrm{q}}$ (where $\mathrm{x}_{\mathrm{q}}$ denotes $\mathrm{x}_{\mathrm{A}}, \mathrm{y}_{\mathrm{A}}$ or $\mathrm{z}_{\mathrm{A}}$ ) can be easily obtained as

$$
\boldsymbol{\Phi}_{, \mathrm{q}}==\left\{\mathrm{R}_{1, \mathrm{q}}(\mathbf{A}), \mathrm{R}_{2, \mathrm{q}}(\mathbf{A}), \ldots, \mathrm{R}_{\mathrm{n}, \mathrm{q}}(\mathbf{A})\right\} \mathbf{R}_{0}^{-1}
$$

where ()$_{, q}$ denotes $\frac{\partial()}{\partial x_{\mathrm{q}}}$

The first-order derivative of radial basis function is written:

$$
\mathrm{R}_{\mathrm{i}, \mathrm{q}}(\mathbf{A})=\frac{\mathrm{x}_{\mathrm{q}}-\mathrm{x}_{\mathrm{iq}}}{\mathrm{R}_{\mathrm{i}}(\mathbf{A})}
$$

\section{Moving Kriging Interpolation}

Kriging is a geostatistical method of spatial data interpolation. The mathematical model of kriging is named after D. G. Krige, who first introduced a version of this spatial prediction process [33]. Kriging has been extensively described by Sacks et al. [34] who proposed the application of kriging in computer experimental. Similar to the Moving Least Square (MLS) approximation [35], the kriging approach can be extended to any sub-domain $\Omega_{\mathrm{A}} \in \Omega$. We call it moving kriging (MK) [31]. Consider the function $\mathrm{u}(\mathbf{A})$ which is defined in the domain $\Omega$ and let the approximation be $\mathrm{u}^{\mathrm{h}}(\mathbf{A})$. To approximate the distribution function $\mathrm{u}$ in sub-domain $\Omega_{\mathrm{A}}$, over a number of nodes $\left\{\mathbf{A}_{\mathrm{i}}\right\}_{\mathrm{i}=1}^{\mathrm{n}}$, the MK interpolation $\mathrm{u}^{\mathrm{h}}(\mathbf{A})$ is defined by

$$
\mathrm{u}^{\mathrm{h}}(\mathbf{A})=\sum_{\mathrm{j}=1}^{\mathrm{m}} \mathrm{p}_{\mathrm{j}}(\mathbf{A}) \mathrm{a}_{\mathrm{j}}+\mathrm{Z}(\mathbf{A})
$$

where $\mathrm{Z}(\mathbf{A})$ is assumed to be the realization of a stochastic process with mean zero, variance $\sigma^{2}$, and non-zero covariance [31].

or

$$
\mathrm{u}^{\mathrm{h}}(\mathbf{A})=\mathbf{p}^{\mathrm{T}}(\mathbf{A}) \widehat{\boldsymbol{\beta}}+\mathbf{e}^{\mathrm{T}}(\mathbf{A}) \mathbf{E}^{-1}(\mathbf{u}-\mathbf{P} \widehat{\boldsymbol{\beta}})
$$

where $\mathbf{P}, \mathbf{E}, \mathbf{e}(\mathbf{A})$ and $\widehat{\boldsymbol{\beta}}$ are given by

$$
\begin{gathered}
\mathbf{P}=\left[\begin{array}{cccc}
\mathrm{p}_{1}\left(\mathbf{A}_{1}\right) & \mathrm{p}_{2}\left(\mathbf{A}_{1}\right) & \ldots & \mathrm{p}_{\mathrm{m}}\left(\mathbf{A}_{1}\right) \\
\mathrm{p}_{1}\left(\mathbf{A}_{2}\right) & \mathrm{p}_{2}\left(\mathbf{A}_{2}\right) & \ldots & \mathrm{p}_{\mathrm{m}}\left(\mathbf{A}_{2}\right) \\
\vdots & \vdots & \ddots & \vdots \\
\mathrm{p}_{1}\left(\mathbf{A}_{\mathrm{n}}\right) & \mathrm{p}_{2}\left(\mathbf{A}_{\mathrm{n}}\right) & \ldots & \mathrm{p}_{\mathrm{m}}\left(\mathbf{A}_{\mathrm{n}}\right)
\end{array}\right] \\
\mathbf{E}=\left[\begin{array}{cccc}
1 & \mathrm{E}\left(\mathbf{A}_{1}, \mathbf{A}_{2}\right) & \ldots & \mathrm{E}\left(\mathbf{A}_{1}, \mathbf{A}_{\mathrm{n}}\right) \\
\mathrm{E}\left(\mathbf{A}_{2}, \mathbf{A}_{1}\right) & 1 & \ldots & \mathrm{E}\left(\mathbf{A}_{2}, \mathbf{A}_{\mathrm{n}}\right) \\
\vdots & \vdots & \ddots & \vdots \\
\mathrm{E}\left(\mathbf{A}_{\mathrm{n}}, \mathbf{A}_{1}\right) & \mathrm{E}\left(\mathbf{A}_{\mathrm{n}}, \mathbf{A}_{2}\right) & \ldots & 1
\end{array}\right]
\end{gathered}
$$




$$
\begin{gathered}
\mathbf{e}(\mathbf{A})=\left\{\begin{array}{c}
\mathrm{E}\left(\mathbf{A}_{1}, \mathbf{A}\right) \\
\vdots \\
\mathrm{E}\left(\mathbf{A}_{\mathrm{n}}, \mathbf{A}\right)
\end{array}\right\} \\
\widehat{\boldsymbol{\beta}}=\left(\mathbf{P}^{\mathrm{T}} \mathbf{E}^{-1} \mathbf{P}\right)^{-1} \mathbf{P}^{\mathrm{T}} \mathbf{E}^{-1} \mathbf{u}
\end{gathered}
$$

$\mathbf{p}(\mathbf{A})$ is a polynomial basis and $\mathbf{a}$ is the vector of coefficients. $m$ denotes the number of terms in the basis, $\mathbf{p}^{\mathrm{T}}(\mathbf{A})=\left\{\mathrm{p}_{1}(\mathbf{A}), \ldots, \mathrm{p}_{\mathrm{m}}(\mathbf{A})\right\}$, for example a linear basis in $3 \mathrm{D}$ is given by

$$
\mathbf{p}^{\mathrm{T}}(\mathbf{A})=\{1, \mathrm{x}, \mathrm{y}, \mathrm{z}\}, \mathrm{m}=4
$$

The correlation function $\mathrm{E}\left(\mathbf{A}_{\mathrm{i}}, \mathbf{A}_{\mathrm{j}}\right)$ is chosen to be Gaussian function:

$$
E\left(\mathbf{A}_{\mathrm{i}}, \mathbf{A}_{\mathrm{j}}\right)=\mathrm{e}^{-\theta \mathrm{r}_{\mathrm{ij}}^{2}}
$$

where $\theta$ is the correlation parameter used to fit the model and chosen to be 1 in this paper.

Similar with $R_{i}(A), r_{i j}=\sqrt{c^{2}+a_{x}^{2}\left(x_{i}-x_{j}\right)^{2}+a_{y}^{2}\left(y_{i}-y_{j}\right)^{2}+a_{z}^{2}\left(z_{i}-z_{j}\right)^{2}}$ here.

Introduce the notation

$$
\begin{gathered}
\mathbf{M}=\left(\mathbf{P}^{\mathrm{T}} \mathbf{E}^{-1} \mathbf{P}\right)^{-1} \mathbf{P}^{\mathrm{T}} \mathbf{E}^{-1} \\
\mathbf{N}=\mathbf{E}^{-1}(\mathbf{I}-\mathbf{P} \mathbf{M})
\end{gathered}
$$

where $\mathbf{I}$ is an $\mathrm{n} \times \mathrm{n}$ unit matrix.

Equation (15) can be rewritten as

$$
\mathrm{u}^{\mathrm{h}}(\mathbf{A})=\left[\mathbf{p}^{\mathrm{T}}(\mathbf{A}) \mathbf{M}+\mathbf{e}^{\mathrm{T}}(\mathbf{A}) \mathbf{N}\right] \mathbf{u}=\sum_{\mathrm{i}=1}^{\mathrm{n}} \phi_{\mathrm{i}}(\mathbf{A}) \mathrm{u}_{\mathrm{i}}=\boldsymbol{\Phi}(\mathbf{A}) \mathbf{u}
$$

where the shape function $\phi_{\mathrm{i}}(\mathrm{A})$ is defined by

$$
\phi_{\mathrm{i}}(\mathbf{A})=\sum_{\mathrm{j}=1}^{\mathrm{m}} \mathrm{p}_{\mathrm{j}}(\mathbf{A}) \mathrm{M}_{\mathrm{ji}}+\sum_{\mathrm{k}=1}^{\mathrm{n}} \mathrm{E}\left(\mathbf{A}_{\mathrm{k}}, \mathbf{A}\right) \mathrm{N}_{\mathrm{ki}}
$$

The partial derivatives of $\phi_{\mathrm{i}}(\mathrm{A})$ against $\mathrm{x}_{\mathrm{q}}$ can be obtained as follows:

$$
\phi_{\mathrm{i}, \mathrm{q}}(\mathbf{A})=\sum_{\mathrm{j}=1}^{\mathrm{m}} \mathrm{p}_{\mathrm{j}, \mathrm{q}}(\mathbf{A}) \mathrm{M}_{\mathrm{ji}}+\sum_{\mathrm{k}=1}^{\mathrm{n}} \mathrm{E}_{\mathrm{,q}}\left(\mathbf{A}_{\mathrm{k}}, \mathbf{A}\right) \mathrm{N}_{\mathrm{ki}}
$$

The partial derivatives of the correlation function $\mathrm{E}\left(\mathbf{A}_{\mathrm{k}}, \mathbf{A}\right)$ against $\mathrm{x}_{\mathrm{q}}$ are

$$
\mathrm{E}_{, \mathrm{q}}\left(\mathbf{A}_{\mathrm{k}}, \mathbf{A}\right)=-2 \theta\left(\mathrm{x}_{\mathrm{q}}-\mathrm{x}_{\mathrm{iq}}\right) \mathrm{E}\left(\mathbf{A}_{\mathrm{k}}, \mathbf{A}\right)
$$

\section{Galerkin Method and Hooke's Law}

For 3D cases, Hooke's law can be generally written, in a matrix form, as 


$$
\boldsymbol{\sigma}=\left\{\begin{array}{c}
\sigma_{\mathbf{x}} \\
\sigma_{\mathbf{y}} \\
\sigma_{\mathbf{z}} \\
\tau_{\mathbf{x y}} \\
\tau_{\mathbf{y z}} \\
\tau_{\mathbf{z x}}
\end{array}\right\}=\left[\begin{array}{llllll}
\mathrm{C}_{11} & \mathrm{C}_{12} & \mathrm{C}_{13} & \mathrm{C}_{14} & \mathrm{C}_{15} & \mathrm{C}_{16} \\
\mathrm{C}_{21} & \mathrm{C}_{22} & \mathrm{C}_{23} & \mathrm{C}_{24} & \mathrm{C}_{25} & \mathrm{C}_{26} \\
\mathrm{C}_{31} & \mathrm{C}_{32} & \mathrm{C}_{33} & \mathrm{C}_{34} & \mathrm{C}_{35} & \mathrm{C}_{36} \\
\mathrm{C}_{41} & \mathrm{C}_{42} & \mathrm{C}_{43} & \mathrm{C}_{44} & \mathrm{C}_{45} & \mathrm{C}_{46} \\
\mathrm{C}_{51} & \mathrm{C}_{52} & \mathrm{C}_{53} & \mathrm{C}_{54} & \mathrm{C}_{55} & \mathrm{C}_{56} \\
\mathrm{C}_{61} & \mathrm{C}_{62} & \mathrm{C}_{63} & \mathrm{C}_{64} & \mathrm{C}_{65} & \mathrm{C}_{66}
\end{array}\right]\left\{\begin{array}{c}
\epsilon_{\mathbf{x}} \\
\epsilon_{\mathbf{y}} \\
\epsilon_{\mathbf{z}} \\
\gamma_{\mathbf{x y}} \\
\gamma_{\mathbf{y z}} \\
\gamma_{\mathbf{z x}}
\end{array}\right\}=\mathbf{C}(\mathrm{x}, \mathrm{y}, \mathrm{z}) \boldsymbol{\varepsilon}
$$

where $\mathrm{C}_{\mathrm{ij}}=\mathrm{C}_{\mathrm{ji}}$ denotes the elasticity tensor. Consider a domain $\Omega$ bounded by $\Gamma$. The total potential energy for the plane stress is obtained:

$$
\Pi=U-W=\frac{1}{2} \int_{\Omega} \boldsymbol{\varepsilon}^{\mathrm{T}} \boldsymbol{\sigma} \mathrm{d} \Omega-\left(\int_{\Omega} \mathbf{u}^{\mathrm{T}} \mathbf{b} \mathrm{d} \Omega+\int_{\Gamma} \mathbf{u}^{\mathrm{T}} \mathbf{t} \mathrm{d} \Gamma\right)
$$

where $U$ is the initial elastic strain energy and $W$ is the external energy, i.e. the sum of contributions from known interior and boundary forces. $\mathbf{b}=\left\{\mathrm{b}_{1}, \mathrm{~b}_{2}\right\}^{\mathrm{T}}$ is the body force vector, and $\mathbf{t}=\left\{\mathrm{t}_{1}, \mathrm{t}_{2}\right\}^{\mathrm{T}}$, in which $\mathrm{t}_{\mathrm{i}}=\sigma_{\mathrm{ij}} \mathrm{n}_{\mathrm{j}}$ is the vector of traction on the boundary and $\mathrm{n}_{\mathrm{j}}$ denotes the component of a unit outward normal vector. The minimum value of total potential energy with respect to each nodal displacements is considered, i.e.,

$$
\delta \Pi=\delta U-\delta W=0
$$

So we have the minimum potential energy principle in Galerkin weak form:

$$
\int_{\boldsymbol{\Omega}} \delta \boldsymbol{\varepsilon}^{\mathrm{T}} \boldsymbol{\sigma} \mathrm{d} \boldsymbol{\Omega}-\int_{\boldsymbol{\Omega}} \delta \mathbf{u}^{\mathrm{T}} \mathbf{b} \mathrm{d} \boldsymbol{\Omega}-\int_{\Gamma} \delta \mathbf{u}^{\mathrm{T}} \mathbf{t} \mathrm{d} \Gamma=0
$$

By the use of shape function, we have $\mathbf{u}=\sum_{\mathrm{i}=1}^{\mathrm{n}} \phi_{\mathrm{i}} \mathbf{u}_{\mathrm{i}}, \boldsymbol{\varepsilon}=\sum_{\mathrm{i}=1}^{\mathrm{n}} \mathbf{B}_{\mathrm{i}} \mathbf{u}_{\mathrm{i}}$, where for $3 \mathrm{D}$ cases, $\mathbf{u}_{\mathrm{i}}{ }^{\mathrm{T}}=\left\{\mathrm{u}_{\mathrm{xi}}, \mathrm{u}_{\mathrm{y}}, \mathrm{u}_{\mathrm{zi}}\right\}, \mathrm{n}$ is the total number of nodes in the sub-domain and

$$
\mathbf{B}_{\mathrm{i}}=\left[\begin{array}{ccc}
\frac{\partial \emptyset_{\mathrm{i}}}{\partial \mathrm{x}} & 0 & 0 \\
0 & \frac{\partial \emptyset_{\mathrm{i}}}{\partial \mathrm{y}} & 0 \\
0 & 0 & \frac{\partial \emptyset_{\mathrm{i}}}{\partial \mathrm{z}} \\
\frac{\partial \emptyset_{\mathrm{i}}}{\partial \mathrm{y}} & \frac{\partial \emptyset_{\mathrm{i}}}{\partial \mathrm{x}} & 0 \\
0 & \frac{\partial \emptyset_{\mathrm{i}}}{\partial \mathrm{z}} & \frac{\partial \emptyset_{\mathrm{i}}}{\partial \mathrm{y}} \\
\frac{\partial \emptyset_{\mathrm{i}}}{\partial \mathrm{z}} & 0 & \frac{\partial \emptyset_{\mathrm{i}}}{\partial \mathrm{x}}
\end{array}\right]
$$

Substituting the expression for all the displacement related components into the weak form Equation (31) yield the global discrete system equations

$$
\mathbf{K U}=\mathbf{F}
$$

where $\mathbf{U}$ is the displacement vector for all the nodes in the entire problem domain and $\mathbf{K}$ is the global stiffness matrix for the problem domain, which is defined:

$$
\mathbf{K}=\int_{\Omega} \mathbf{B}^{\mathrm{T}} \mathbf{C}(\mathrm{x}, \mathrm{y}, \mathrm{z}) \mathbf{B} \mathrm{d} \boldsymbol{\Omega}
$$

Note that for woven fabric composites, in terms of different locations in the model, in matrix or in yarns for example, the constitutive matrix $\mathbf{C}(\mathrm{x}, \mathrm{y}, \mathrm{z})$ is different. Also according to the direction of the fibres in the yarns, $\mathbf{C}(\mathrm{x}, \mathrm{y}, \mathrm{z})$ varies as well.

$\mathbf{F}$ is the nodal force vector which is: 


$$
\mathbf{F}=\int_{\Omega} \boldsymbol{\Phi}^{\mathrm{T}} \mathbf{b} \mathrm{d} \boldsymbol{\Omega}+\int_{\Gamma_{\sigma}} \boldsymbol{\Phi}^{\mathrm{T}} \mathbf{t} \mathrm{d} \Gamma
$$

where $\Gamma_{\sigma}$ denotes the boundary on which the traction is given. For concentrated forces acting at the node $\mathrm{i}$, the nodal force vector can be determined directly by

$$
F_{i}=\left\{F_{1}^{i}, F_{2}^{i}, F_{3}^{i}\right\}^{T}
$$

For isotropic material, the matrix part of the woven composites for instance, the constitutive matrix $\mathbf{C}(\mathrm{x}, \mathrm{y}, \mathrm{z})$ can be simply obtained

$$
\mathbf{C}=\left[\begin{array}{cccccc}
\mathrm{C}_{11} & \mathrm{C}_{12} & \mathrm{C}_{12} & 0 & 0 & 0 \\
\mathrm{C}_{12} & \mathrm{C}_{11} & \mathrm{C}_{12} & 0 & 0 & 0 \\
\mathrm{C}_{12} & \mathrm{C}_{12} & \mathrm{C}_{11} & 0 & 0 & 0 \\
0 & 0 & 0 & \mathrm{C}_{44} & 0 & 0 \\
0 & 0 & 0 & 0 & \mathrm{C}_{44} & 0 \\
0 & 0 & 0 & 0 & 0 & \mathrm{C}_{44}
\end{array}\right]
$$

\section{where $\mathrm{C}_{44}=\left(\mathrm{C}_{11}-\mathrm{C}_{12}\right) / 2$.}

Considering the composites which are of transversely isotropic material with axis of transverse isotropy along the corresponding yarn axis, which is $\mathrm{x}$ and $\mathrm{y}$, the constitutive matrix $\mathbf{C}(\mathrm{x}, \mathrm{y}, \mathrm{z})$ will be as follows:

$$
\begin{gathered}
\mathbf{C}_{\mathrm{x}}=\left[\begin{array}{cccccc}
\mathrm{C}_{11} & \mathrm{C}_{12} & \mathrm{C}_{12} & 0 & 0 & 0 \\
\mathrm{C}_{12} & \mathrm{C}_{22} & \mathrm{C}_{23} & 0 & 0 & 0 \\
\mathrm{C}_{12} & \mathrm{C}_{23} & \mathrm{C}_{22} & 0 & 0 & 0 \\
0 & 0 & 0 & \mathrm{C}_{44} & 0 & 0 \\
0 & 0 & 0 & 0 & \mathrm{C}_{55} & 0 \\
0 & 0 & 0 & 0 & 0 & \mathrm{C}_{44}
\end{array}\right] \\
\mathbf{C}_{\mathrm{y}}=\left[\begin{array}{cccccc}
\mathrm{C}_{22} & \mathrm{C}_{12} & \mathrm{C}_{23} & 0 & 0 & 0 \\
\mathrm{C}_{12} & \mathrm{C}_{11} & \mathrm{C}_{12} & 0 & 0 & 0 \\
\mathrm{C}_{23} & \mathrm{C}_{12} & \mathrm{C}_{22} & 0 & 0 & 0 \\
0 & 0 & 0 & \mathrm{C}_{44} & 0 & 0 \\
0 & 0 & 0 & 0 & \mathrm{C}_{44} & 0 \\
0 & 0 & 0 & 0 & 0 & \mathrm{C}_{55}
\end{array}\right]
\end{gathered}
$$

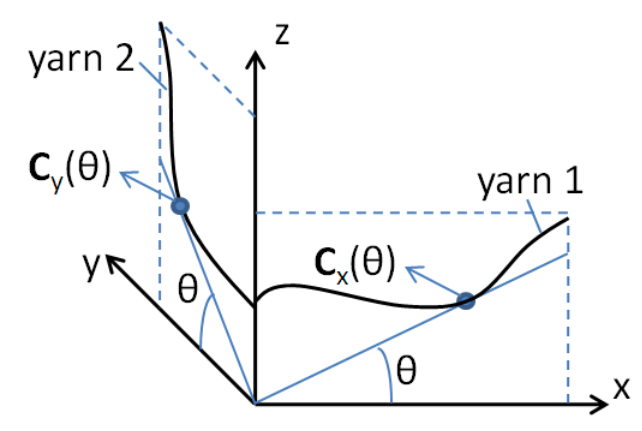

Figure 2 Example of constitutive matrixes for undulated yarns.

In terms of the composites with fibres with an undulation angle, $\theta$, such as in $\mathrm{x}$-z plane or in $y-z$ plane, as shown in Figure 2, the constitutive matrix can be transformed by:

$$
\mathbf{C}(\theta)=\mathbf{T}_{\mathbf{E}} \cdot \mathbf{C}^{\prime} \cdot \mathbf{T}_{\mathbf{E}}^{\mathrm{T}}
$$


Where $\mathbf{T}_{\mathbf{E}}$ is the transformation matrix as given below:

$$
\mathbf{T}_{\mathbf{E}}=\left[\begin{array}{cccccc}
\mathrm{t}_{11}{ }^{2} & \mathrm{t}_{12}{ }^{2} & \mathrm{t}_{13}{ }^{2} & 2 \mathrm{t}_{11} \mathrm{t}_{12} & 2 \mathrm{t}_{12} \mathrm{t}_{13} & 2 \mathrm{t}_{11} \mathrm{t}_{13} \\
\mathrm{t}_{21}{ }^{2} & \mathrm{t}_{22}{ }^{2} & \mathrm{t}_{23}{ }^{2} & 2 \mathrm{t}_{21} \mathrm{t}_{22} & 2 \mathrm{t}_{22} \mathrm{t}_{23} & 2 \mathrm{t}_{21} \mathrm{t}_{23} \\
\mathrm{t}_{31}{ }^{2} & \mathrm{t}_{32}{ }^{2} & \mathrm{t}_{33}{ }^{2} & 2 \mathrm{t}_{31} \mathrm{t}_{32} & 2 \mathrm{t}_{32} \mathrm{t}_{33} & 2 \mathrm{t}_{31} \mathrm{t}_{33} \\
\mathrm{t}_{11} \mathrm{t}_{21} & \mathrm{t}_{12} \mathrm{t}_{22} & \mathrm{t}_{13} \mathrm{t}_{23} & \mathrm{t}_{11} \mathrm{t}_{22}+\mathrm{t}_{12} \mathrm{t}_{21} & \mathrm{t}_{12} \mathrm{t}_{23}+\mathrm{t}_{13} \mathrm{t}_{22} & \mathrm{t}_{11} \mathrm{t}_{23}+\mathrm{t}_{13} \mathrm{t}_{21} \\
\mathrm{t}_{21} \mathrm{t}_{31} & \mathrm{t}_{22} \mathrm{t}_{32} & \mathrm{t}_{23} \mathrm{t}_{33} & \mathrm{t}_{21} \mathrm{t}_{32}+\mathrm{t}_{22} \mathrm{t}_{31} & \mathrm{t}_{22} \mathrm{t}_{33}+\mathrm{t}_{23} \mathrm{t}_{32} & \mathrm{t}_{21} \mathrm{t}_{33}+\mathrm{t}_{23} \mathrm{t}_{31} \\
\mathrm{t}_{31} \mathrm{t}_{11} & \mathrm{t}_{32} \mathrm{t}_{12} & \mathrm{t}_{33} \mathrm{t}_{13} & \mathrm{t}_{11} \mathrm{t}_{32}+\mathrm{t}_{12} \mathrm{t}_{31} & \mathrm{t}_{12} \mathrm{t}_{33}+\mathrm{t}_{13} \mathrm{t}_{32} & \mathrm{t}_{11} \mathrm{t}_{33}+\mathrm{t}_{13} \mathrm{t}_{31}
\end{array}\right]
$$

For rotating the local coordinates in $\mathrm{x}-\mathrm{z}$ plane at angle $\theta$, yarn 1 in Figure 2 for example, we use

$$
\left[\begin{array}{lll}
t_{11} & t_{12} & t_{13} \\
t_{21} & t_{22} & t_{23} \\
t_{31} & t_{32} & t_{33}
\end{array}\right]=\left[\begin{array}{ccc}
\cos \theta & 0 & -\sin \theta \\
0 & 1 & 0 \\
\sin \theta & 0 & \cos \theta
\end{array}\right]
$$

So the constitutive matrix in global coordinate system for yarns with an angle $\theta$ in x-z plane becomes

$$
\mathbf{C}_{\mathbf{x}}(\theta)=\left[\begin{array}{cccccc}
\mathrm{C}_{11^{\prime}} & \mathrm{C}_{12}{ }^{\prime} & \mathrm{C}_{13^{\prime}} & 0 & 0 & \mathrm{C}_{16^{\prime}} \\
\mathrm{C}_{12^{\prime}} & \mathrm{C}_{22^{\prime}} & \mathrm{C}_{23^{\prime}} & 0 & 0 & \mathrm{C}_{26^{\prime}} \\
\mathrm{C}_{13^{\prime}} & \mathrm{C}_{23^{\prime}} & \mathrm{C}_{33^{\prime}} & 0 & 0 & \mathrm{C}_{36^{\prime}} \\
0 & 0 & 0 & \mathrm{C}_{44^{\prime}} & \mathrm{C}_{45^{\prime}}{ }^{\prime} & 0 \\
0 & 0 & 0 & \mathrm{C}_{45^{\prime}} & \mathrm{C}_{55^{\prime}} & 0 \\
\mathrm{C}_{16^{\prime}} & \mathrm{C}_{26^{\prime}} & \mathrm{C}_{36^{\prime}} & 0 & 0 & \mathrm{C}_{66^{\prime}}
\end{array}\right]=\mathbf{T}_{\mathbf{E}} \cdot \mathbf{C}_{\mathbf{x}} \cdot \mathbf{T}_{\mathbf{E}}{ }^{\mathrm{T}}
$$

Simply transforming the above constitutive matrix, we have

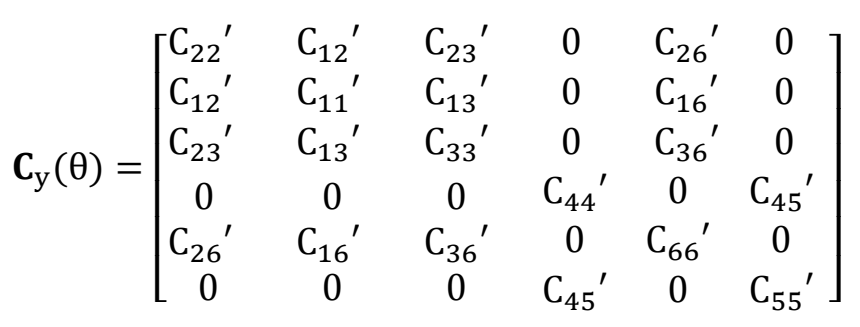

In the case of 3D orthogonal woven composites, the undulation angle $\theta$, which is a function of the coordinates $\mathrm{x}$ and $\mathrm{y}$, determines the direction of the fibres in the yarns, and is related to the geometry of the unit cell model. As it is a case of wavy fibres, the constitutive matrices, Eq. 43 and Eq. 44, are local in a sense that their components being functions of coordinates $x$ and $y$, which makes obvious difference from the case of respective composite having straight fibres.

\section{Geometry of the Unit Cell Model}

3D orthogonal woven composites is one of the most common choices for finite element analysis because of its relatively simple weave pattern comparing with other 3D woven composites. As stated by Dickinson et al. [17], there is no interlacing between the $\mathrm{x}$ and $\mathrm{y}$ direction yarns in the 3D orthogonal preform; only the $\mathrm{z}$ direction yarns are interlaced with the crimp and the yarn curvature is restricted to the outside of the preform, illustrated in Figure 3. 


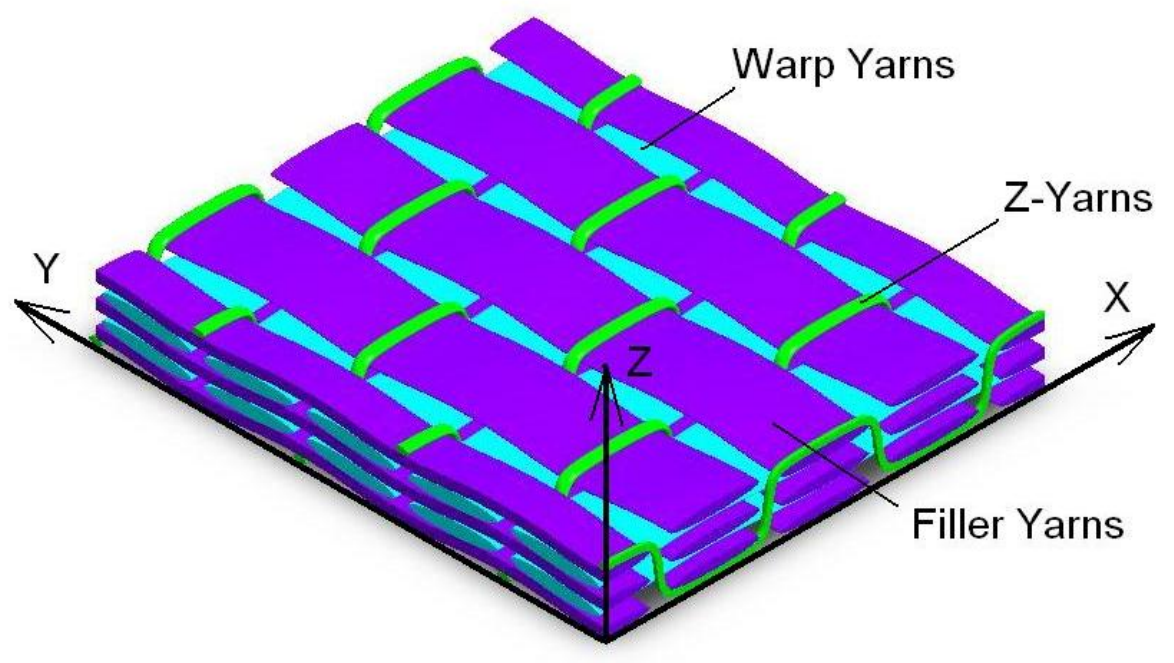

Figure 3 Representative model of $3 D$ orthogonal woven fabric.

Three layers of filler yarns in purple, two layers of warp yarns in blue and Z-yarns in green

\section{Straight-edge Unit Cell Model}

In this approach proposed by A. E. Bogdanovich [11], the straight-edge unit cell model contains three layers of filler yarns, two layers of warp yarns and two halves of the inclined Z-yarns, as shown in Figure 4, and is generated according to direct measurements of the produced fabric and composites.

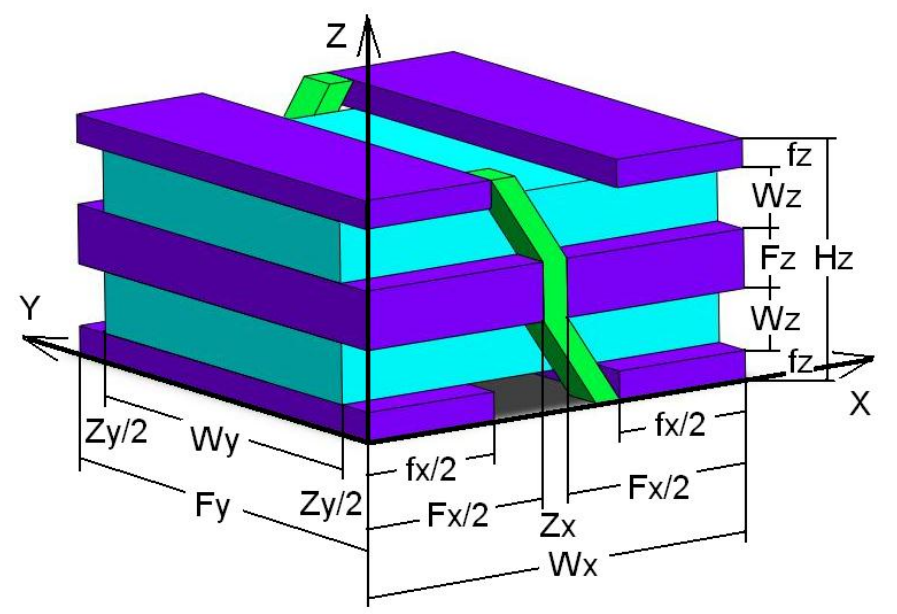

Figure 4 Straight-edge Unit cell model of 3D orthogonal woven composites[36]

However the straight-edge unit cell model does not account for indentation of Z-yarns into respective filler yarns on the fabric surfaces, as stated by Bogdanovich [11], this leads to the discrepancies between the unit cell model and the fabricated composites: thickness and total fibre volume fraction. Thus, the straight-edge unit cell model was generated in the way that the extra resin on both faces is not contained, for carrying out the stress analyses of 3D orthogonal woven composites.

The determined characteristics of this geometric model are listed in Table 1. 


\begin{tabular}{cccccccccccc}
\hline fx & fz & Fx & Fy & Fz & Wx & Wy & Wz & Zx & Zy & Zz & Hz \\
\hline 3.082 & 0.292 & 4.326 & 5.08 & 0.614 & 4.618 & 4.171 & 0.637 & 0.292 & 0.909 & 0.292 & 2.472 \\
\hline
\end{tabular}

\section{Smooth Fabric Unit Cell Model}

In this paper, a more realistic representation of the $3 \mathrm{D}$ orthogonal woven fabric model is formulated and implemented into meshfree method. As the undulations and the cross-sections of yarns are formulated into curved shapes, it is referred to as smooth fabric model. For comparison, Figure 5 shows a representative smooth fabric model with the same amount of yarns taking into consideration as the straight-edge unit cell model. All the basic dimensions (listed in Table 1) of different yarns used for the smooth fabric model are kept the same as the straight-edge unit cell model shown in Figure 3. Lower yarn faction in the smooth fabric model leads to some difference between the results of straight-edge and smooth fabric model as the fibre volume faction in the yarns is kept the same in both two models.

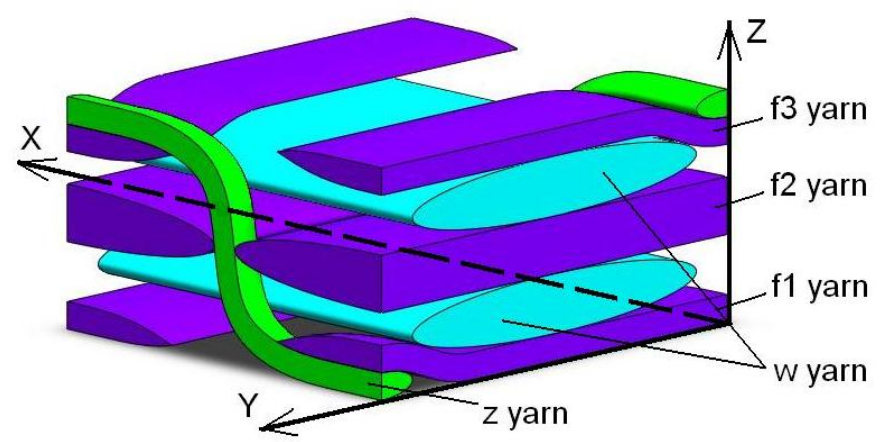

Figure 5 Representative smooth fabric model of $3 D$ orthogonal woven fabric.

Due to the symmetry, while implementing meshfree method, only a quarter of the representative model in Figure 5 needs to be considered as the unit cell model, as represented in Figure 6. In this approach, the fibres in yarn volume are unidirectional and smooth distributed along the filler/warp/Z directions. The geometry is formulated as below:

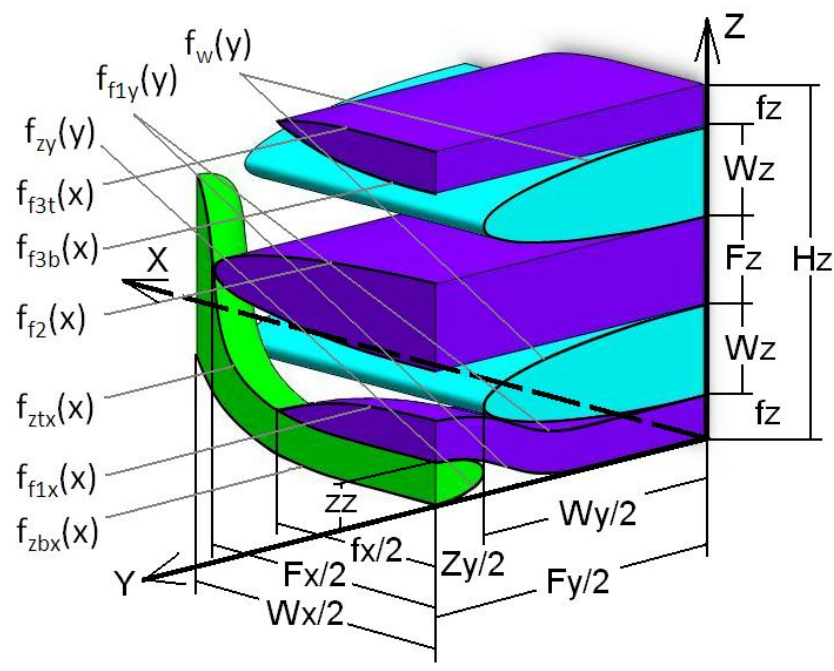

Figure 6 Smooth fabric unit cell model of $3 D$ orthogonal woven fabric.

- z yarn 
Suppose the variation of the Z-yarn fibres are based on a part of arctangent function, $\left.\operatorname{atan}(\mathrm{x})\right|_{-15 \leq x \leq 15}$, the functions of the bottom and the top fibres can be written:

$$
\begin{aligned}
& \mathrm{f}_{\mathrm{zxb}}(\mathrm{x})=\mathrm{c}_{0} * \operatorname{atan}\left[\mathrm{a}_{0}\left(\mathrm{x}-\frac{\mathrm{Zz}}{2}\right)+\mathrm{b}_{0}\right]+\mathrm{d}_{0}-\frac{\mathrm{Zz}}{2} \\
& \mathrm{f}_{\mathrm{zxt}}(\mathrm{x})=\mathrm{c}_{0} * \operatorname{atan}\left[\mathrm{a}_{0}\left(\mathrm{x}+\frac{\mathrm{Zz}}{2}\right)+\mathrm{b}_{0}\right]+\mathrm{d}_{0}+\frac{\mathrm{Zz}}{2}
\end{aligned}
$$

where $\mathrm{a}_{0}, \mathrm{~b}_{0}, \mathrm{c}_{0}, \mathrm{~d}_{0}$ are the parameters to determine the shape of the fibres according to the dimensions of the unit cell model, as $\mathrm{a}_{0}=\frac{15-(-15)}{\mathrm{Wx}}, \mathrm{b}_{0}=-15, \mathrm{c}_{0}=\frac{\mathrm{hz}-\mathrm{Zz}}{\operatorname{atan}(15)-\mathrm{atan}(-15)}$ and $\mathrm{d}_{0}=\frac{\mathrm{Zz}}{2}-\mathrm{c}_{0} * \operatorname{atan}(-15)$. Note that the range of the "atan" function is chosen to be from 15 to 15 in order to fit the shape of inclined $Z$ yarn.

We assume that the configuration of $\mathrm{Z}$-yarn volume on section $\mathrm{x}=0$ is half ellipse:

$$
f_{z y}(y)= \pm b_{1} \sqrt{1-\left(\frac{y-F y / 2}{a_{1}}\right)^{2}}+c_{1}
$$

where the coefficients are determined according to the dimensions of the unit cell model, as $a_{1}=\frac{\mathrm{Zy}}{2}, b_{1}=\frac{f_{\mathrm{zxt}}(\mathrm{x}=0)-\mathrm{f}_{\mathrm{zxb}}(\mathrm{x}=0)}{2}$ and $\mathrm{c}_{1}=\frac{\mathrm{f}_{\mathrm{zxt}}(\mathrm{x}=0)+\mathrm{f}_{\mathrm{zxb}}(\mathrm{x}=0)}{2}$.

Therefore, the bottom and top surfaces of the Z-yarn volume can be written as

$$
\begin{aligned}
& f_{z b o t}(x, y)=-b_{1} \sqrt{1-\left(\frac{y-F y / 2}{a_{1}}\right)^{2}}+c_{1}+f_{z x b}(x) \\
& f_{z t o p}(x, y)=b_{1} \sqrt{1-\left(\frac{y-F y / 2}{a_{1}}\right)^{2}}+c_{1}+f_{z x t}(x)
\end{aligned}
$$

The slope of the Z-yarn fibre which starts at $\mathrm{z}=\mathrm{z}_{0}$ is obtained as

$$
\frac{\mathrm{df}_{\mathrm{zx}}(\mathrm{x})}{\mathrm{dx}}=\frac{\mathrm{c}_{0} * \mathrm{a}_{0}}{1+\left[\mathrm{a}_{0}\left(\mathrm{x}-\frac{\mathrm{Zz}}{2}+\mathrm{z}_{0}\right)+\mathrm{b}_{0}\right]^{2}}
$$

Therefore, the rotating angle $\theta$ of the fibre, which is needed for determining the constitutive matrix $\mathbf{C}(\mathrm{x}, \mathrm{y}, \mathrm{z})$, can be calculated by $\theta=\operatorname{atan}\left[\frac{\mathrm{df}_{\mathrm{zx}}(\mathrm{x})}{\mathrm{dx}}\right]$ for different positions on the fibre.

\section{- f1 yarn}

The undulation of the $\mathrm{f} 1$ yarn is constructed by two parts: straight part when $0 \leq \mathrm{y} \leq \frac{\mathrm{Fy}}{2}-$ $1.5 Z y$; and curve part when $\frac{\mathrm{Fy}}{2}-1.5 Z y \leq \mathrm{y} \leq \frac{\mathrm{Fy}}{2}$. The function of sine is used as the basic function of the curve part. The curve part is formulated as below:

$$
\mathrm{f}_{\mathrm{f} 1 \mathrm{y}}(\mathrm{y})=\mathrm{c}_{2} * \sin \left[\mathrm{a}_{2}\left(\mathrm{y}-\mathrm{b}_{2}\right)\right]+\mathrm{d}_{2}+\mathrm{z}_{0}
$$


where $\mathrm{z}_{0}$ denotes where the fibre starts at. For example, when $\mathrm{z}_{0}=0, \mathrm{f}_{\mathrm{f} 1 \mathrm{y}}(\mathrm{y})$ becomes the bottom fibre in $\mathrm{f} 1$ yarn; when $\mathrm{z}_{0}=\mathrm{fz}, \mathrm{f}_{\mathrm{f} 1 \mathrm{y}}(\mathrm{y})$ becomes the top fibre in $\mathrm{f1}$ yarn. $\mathrm{a}_{2}, \mathrm{~b}_{2}, \mathrm{c}_{2}, \mathrm{~d}_{2}$ are the coefficients determined as $a_{2}=\frac{\pi}{1.5 * \mathrm{Zy}}, b_{2}=\frac{\mathrm{fy}}{2}-\frac{1.5 * \mathrm{Zy}}{2}, \mathrm{c}_{2}=\frac{\mathrm{f}_{\mathrm{zxt}}(\mathrm{x}=0)}{2}$ and $\mathrm{d}_{2}=$ $\frac{\mathrm{f}_{\mathrm{zxt}}(\mathrm{x}=0)}{2}$.

The top outline of the cross section of $\mathrm{f} 1$ yarn on surface of $\mathrm{y}=\frac{\mathrm{Fy}}{2}$ is formulated to be

$$
f_{f 1 x}(x)=-a_{3} * x^{2}+b_{3}
$$

where the coefficients are determined as $a_{3}=\frac{b_{3}-f_{z x t}\left(x=\frac{f x}{2}\right)}{\left(\frac{f x}{2}\right)^{2}}$ and $b_{3}=f z+f_{z x t}(x=0)$.

Thus the top and bottom surfaces of f1 yarn can be expressed as

when $0 \leq \mathrm{y} \leq \frac{\text { Fy }}{2}-1.5 Z y$ :

$$
\begin{aligned}
& f_{\text {f1 top }}(x, y)=-a_{3} * x^{2}+f z \\
& f_{\text {f1 bot }}(x, y)=f_{z x t}(x)-f_{z x t}(x=0)
\end{aligned}
$$

when $\frac{\text { Fy }}{2}-1.5 Z y \leq \mathrm{y} \leq \frac{\text { Fy }}{2}$ :

$$
\begin{aligned}
& f_{f 1 \text { top }}(x, y)=\left.f_{f 1 y}(y)\right|_{z_{0}=f z}-a_{3} * x^{2} \\
& f_{f 1 \text { bot }}(x, y)=\left.f_{f 1 y}(y)\right|_{z_{0}=0}+f_{z x t}(x)-f_{z x t}(x=0)
\end{aligned}
$$

The slope of the fibre becomes

$$
\frac{\mathrm{df}_{\mathrm{f} 1 \mathrm{y}}(\mathrm{y})}{\mathrm{dy}}=\mathrm{c}_{2} * \mathrm{a}_{2} * \sin \left[\mathrm{a}_{2}\left(\mathrm{y}-\mathrm{b}_{2}\right)\right]
$$

So the rotating angle $\theta=\operatorname{atan}\left[\frac{d f_{f 1 y}(y)}{d y}\right]$.

- f2 yarn

The shape of the cross section of $\mathrm{f} 2$ yarn is constructed to be half ellipse:

$$
f_{f 2}(x)= \pm b_{4} \sqrt{1-\left(\frac{x}{a_{4}}\right)^{2}}+c_{4}
$$

where $\mathrm{a}_{4}=\frac{\mathrm{Fx}}{2}, \mathrm{~b}_{4}=\frac{\mathrm{Fz}}{2}, \mathrm{c}_{4}=\frac{\mathrm{hz}}{2}$

so the top and bottom surfaces of filler yarn 2 can be written as

$$
f_{f 2 t o p}(x, y)=b_{4} \sqrt{1-\left(\frac{x}{a_{4}}\right)^{2}}+c_{4}
$$




$$
f_{\text {f } 2 b o t}(x, y)=-b_{4} \sqrt{1-\left(\frac{x}{a_{4}}\right)^{2}}+c_{4}
$$

- f3 yarn

For $\mathrm{f3}$ yarn, the cross section shape is symmetric with the cross section of f1 yarn. Since the fibres are straight along y direction, the top and bottom surfaces of the $\mathrm{f} 3$ yarn can be directly formulated as

$$
\begin{gathered}
f_{\text {f3top }}(x, y)=f_{z x b}(W x-x)+h z-f_{z x b}(x=W x) \\
f_{\text {f3bot }}(x, y)=h z-f z+a_{3} * x^{2}
\end{gathered}
$$

where the coefficient $\mathrm{a}_{3}$ has the same value as the one for $\mathrm{f} 1$ yarn.

- w yarns

The warp yarn fibres are straight along $\mathrm{x}$ direction and the function of ellipse is used to formulate the cross section. So the top and bottom surfaces of w yarns can be written as

$$
\begin{aligned}
& f_{w t o p}(x, y)=b_{5} \sqrt{1-\left(\frac{y}{a_{5}}\right)^{2}}+c_{5,6} \\
& f_{w b o t}(x, y)=-b_{5} \sqrt{1-\left(\frac{y}{a_{5}}\right)^{2}}+c_{5,6}
\end{aligned}
$$

where $a_{5}=\frac{W y}{2}, b_{5}=\frac{W z}{2}, c_{5}=f z+\frac{W z}{2}$ for the lower warp yarn, and $c_{6}=f z+F z+\frac{3 W z}{2}$ for the upper warp yarn.

\section{Results and Discussion}

Once the geometry of the yarns is defined, the global stiffness matrix $\mathbf{K}$ for the whole unit cell can be obtained by Equation (34). The undulated yarns and matrix part are expressed in the (34) by different $\mathbf{C}(x, y, z)$ of different integration points, as depicted in Figure 7 . Therefore, when obtaining the global discrete system equations (33), each integration point is considered as the field node and carries its own material properties while the nodes are only used to generate the shape functions to the field nodes. In this case, it is not necessary to distribute nodes or integration points on the interfaces between matrix \& yarn or yarn \& yarn; also there are no boundary conditions or discontinuous functions needed along the interfaces since perfect bond between constituents is assumed. The aim of formulating the geometry in this Meshfree approach is not only to determine the position for each integration point but also to obtain the undulation angle $\theta$ of $\mathbf{C}(x, y, z)$ when the integration point is located inside the yarns. After the global discrete system equation (33) is assembled, boundary conditions are applied to the relevant nodes, Equation (33) can then be solved to obtain the displacement field. It can be seen that one significant advantage of the proposed Meshfree approach is that the complexity of the yarn shape hardly affects the simplicity and efficiency of the numerical process; in other words, the approach can be a general method for numerical homogenization of composite materials. 


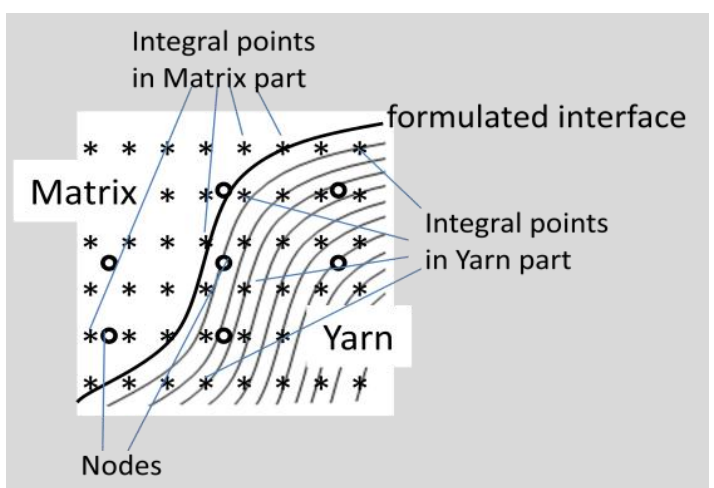

Figure 7 Meshfree approach based on Galerkin method for composites

The straight-edge unit cell model was constructed to determine its elastic properties by Bogdanovich [11]. The manufactured preform is called $93 \mathrm{oz}$ fabric which has areal weight $3.46 \mathrm{~kg} / \mathrm{m}^{2}$, or $93 \mathrm{oz} / \mathrm{yd}^{2}$. Both warp layers are made of 250 yield/lb S-2 glass roving; 5 double ends/inch insertion used; $50.8 \%$ of total fibre amount in the preform is placed in warp direction. Two outer filler layers are made of 750 yield/lb S-2 glass roving, while the middle filler layer is made of 250 yield/lb S-2 glass roving; double yarn insertion with 5.5 picks/inch used in filler direction, Z-yarn is 1250 yield/lb S-2 glass roving with 5 ends/inch insertion. However the elastic properties of warp-, filler-, and Z-composites applied to the straight-edge unit cell model in finite element numerical examples are the effective elastic properties of unidirectional composites made of S-2 glass fibre roving (60\% fibre volume faction) and Dow Deroakane 8084 Vinyl Ester-Epoxy resin which have been predicted in [36] from 3D analysis of the respective unidirectional composites, as shown in Table 2. These effective elastic yarn properties are utilized for both straight-edge and smooth fabric unit cell model.

Table 2 The effective elastic properties of yarns [36]

\begin{tabular}{ccccccccc}
\hline $\mathrm{E}_{1}(\mathrm{GPa})$ & $\mathrm{E}_{2}(\mathrm{GPa})$ & $\mathrm{E}_{3}(\mathrm{GPa})$ & $\mathrm{G}_{12}(\mathrm{GPa})$ & $\mathrm{G}_{13}(\mathrm{GPa})$ & $\mathrm{G}_{23}(\mathrm{GPa})$ & $\mathrm{v}_{12}$ & $\mathrm{v}_{13}$ & $\mathrm{v}_{23}$ \\
\hline 53.12 & 14.66 & 14.66 & 4.24 & 4.24 & 5.78 & 0.266 & 0.266 & 0.268 \\
\hline
\end{tabular}

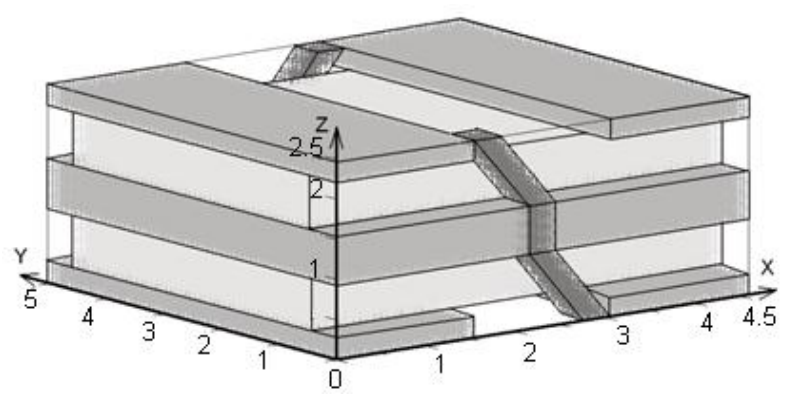

(a)

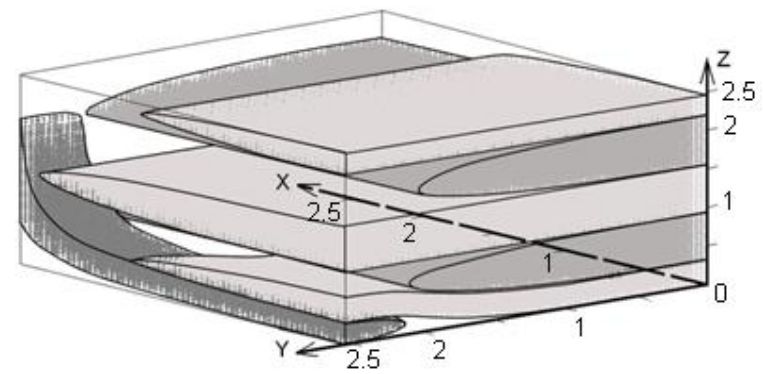

(b)

Figure 8 Geometry of (a) straight-edge and (b) smooth fabric unit cell model generated by meshfree approach, shown by plotting integration points in different yarns 


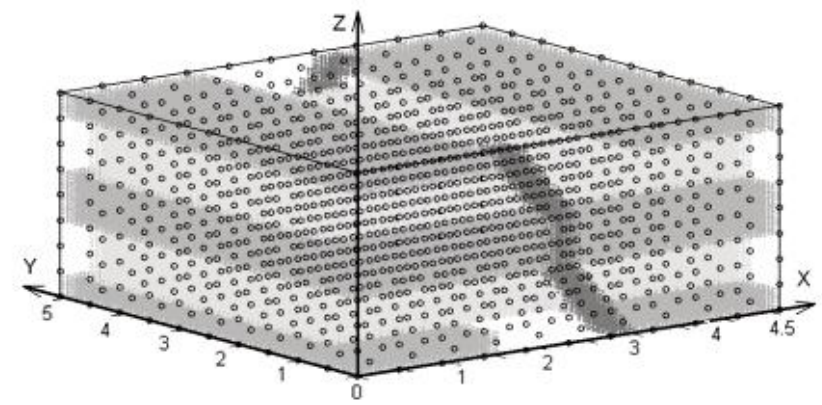

(a)

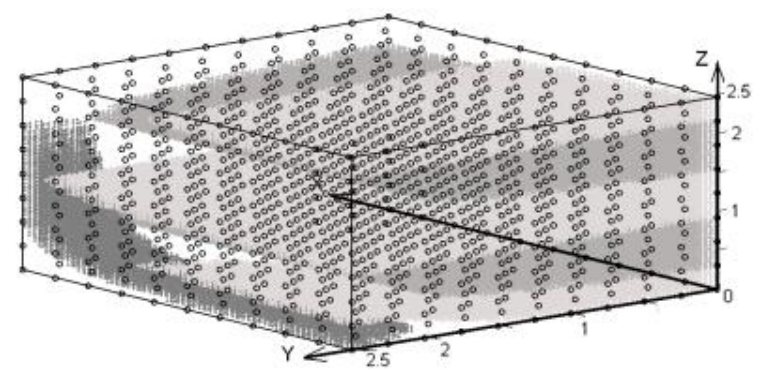

(b)

Figure 9 Uniform distributions $(11 \times 11 \times 9)$ of nodes in (a) straight-edge and (b) smooth fabric unit cell model.

The geometry of the unit cell models generated by meshfree method can be shown by plotting Gaussian integration points, as presented in Figure 8. The nodes are uniformly distributed $(\mathrm{Nx} \times \mathrm{Ny} \times \mathrm{Nz}=11 \times 11 \times 9=1089$ nodes used to compare with FE results in this paper), as shown in Figure 9, and the scale factors in the shape functions are selected to be $\mathrm{a}_{\mathrm{x}}=\frac{\mathrm{Nx}}{\mathrm{Wx}}, \mathrm{a}_{\mathrm{y}}=$ $\frac{\mathrm{Ny}}{\mathrm{Fy}}$ and $\mathrm{a}_{\mathrm{z}}=\frac{\mathrm{Nz}}{\mathrm{Hz}}$. The minimum amount of support nodes inside sub-domains is chosen to be 12 in this paper.

The homogenized constitutive property of the 3D orthogonal woven composites model can be written as

$$
\overline{\mathbf{C}}=\left[\begin{array}{cccccc}
\overline{\mathrm{C}_{11}} & \overline{\mathrm{C}_{12}} & \overline{\mathrm{C}_{13}} & 0 & 0 & 0 \\
\overline{\mathrm{C}_{12}} & \overline{\mathrm{C}_{22}} & \overline{\mathrm{C}_{23}} & 0 & 0 & 0 \\
\overline{\mathrm{C}_{13}} & \overline{\mathrm{C}_{23}} & \overline{\mathrm{C}_{33}} & 0 & 0 & 0 \\
0 & 0 & 0 & \overline{\mathrm{C}_{44}} & 0 & 0 \\
0 & 0 & 0 & 0 & \overline{\mathrm{C}_{55}} & 0 \\
0 & 0 & 0 & 0 & 0 & \overline{\mathrm{C}_{66}}
\end{array}\right]
$$

There are no no-orthotropic terms since when we consider the whole structure of 3D orthogonal woven composites as an assembly of many unit cell models, the local stiffness components generated by the inclined $\mathrm{Z}$ yarn in unit cell models cancel each other out and lead to zero value after assembly. However, due to various possible computational inaccuracies, the results of $\overline{\mathbf{C}}$ obtained are not absolutely symmetric, therefore, it is advisable to take the average values of $\overline{\mathrm{C}_{12}} \& \overline{\mathrm{C}_{21}}, \overline{\mathrm{C}_{13}} \& \overline{\mathrm{C}_{31}}$ and $\overline{\mathrm{C}_{23}} \& \overline{\mathrm{C}_{32}}$ as the final results of $\overline{\mathrm{C}_{12}}, \overline{\mathrm{C}_{13}}$ and $\overline{\mathrm{C}_{23}}$.

The relation between the elastic characteristics and the effective components in $\overline{\mathbf{C}}$ for orthogonal material can be simply obtained from the compliances matrix $\overline{\mathbf{A}}$ : 


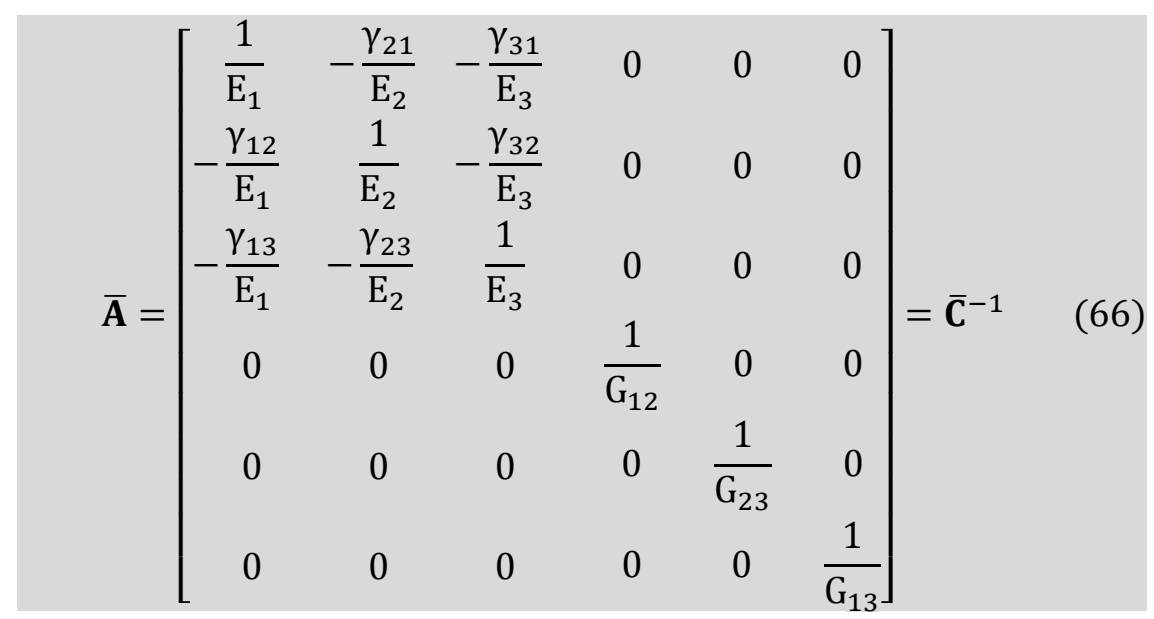

Boundary conditions of applied strains are used since the coefficients in $\overline{\mathbf{C}}$ can be simply obtained by calculating the average stresses in this way. There are other ways of adding boundary conditions, for example periodic boundary conditions, which can also be implemented into Meshfree methods, however, in order to determine the coefficients in $\overline{\mathbf{C}}$ for this case, the boundary conditions below are considered to be more straightforward.

When boundary conditions of $\varepsilon_{\mathrm{x}}=1$ and $\varepsilon_{\mathrm{y}}=\varepsilon_{\mathrm{z}}=\gamma_{\mathrm{xy}}=\gamma_{\mathrm{yz}}=\gamma_{\mathrm{zx}}=0$ are applied:

$$
\begin{aligned}
& x=0: u_{x}=0 ; \tau_{x y}=\tau_{z x}=0 ; \quad x=W x: u_{x}=W x ; \tau_{x y}=\tau_{z x}=0 ; \\
& y=0: u_{y}=0 ; \tau_{x y}=\tau_{y z}=0 ; \quad y=F y: u_{y}=0 ; \quad \tau_{x y}=\tau_{y z}=0 ; \\
& z=0: u_{z}=0 ; \tau_{y z}=\tau_{z x}=0 ; \quad z=H z: u_{z}=0 ; \quad \tau_{y z}=\tau_{z x}=0 ;
\end{aligned}
$$

$\overline{\mathrm{C}_{11}}, \overline{\mathrm{C}_{12}}$ and $\overline{\mathrm{C}_{13}}$ can be approximated:

$$
\begin{aligned}
& \overline{C_{11}}=\overline{\sigma_{x}}=\frac{\int \sigma_{x} d V}{V} \\
& \overline{C_{12}}=\overline{\sigma_{y}}=\frac{\int \sigma_{y} d V}{V} \\
& \overline{C_{13}}=\overline{\sigma_{z}}=\frac{\int \sigma_{z} d V}{V}
\end{aligned}
$$

Similarly, when boundary conditions of $\varepsilon_{\mathrm{y}}=1$ and $\varepsilon_{\mathrm{x}}=\varepsilon_{\mathrm{z}}=\gamma_{\mathrm{xy}}=\gamma_{\mathrm{yz}}=\gamma_{\mathrm{zx}}=0$ are applied:

$$
\begin{aligned}
& x=0: u_{x}=0 ; \tau_{x y}=\tau_{z x}=0 ; x=W x: u_{x}=0 ; \quad \tau_{x y}=\tau_{z x}=0 ; \\
& y=0: u_{y}=0 ; \tau_{x y}=\tau_{y z}=0 ; \quad y=F y: u_{y}=F y ; \quad \tau_{x y}=\tau_{y z}=0 ; \\
& z=0: u_{z}=0 ; \tau_{y z}=\tau_{z x}=0 ; \quad z=H z: u_{z}=0 ; \quad \tau_{y z}=\tau_{z x}=0 ;
\end{aligned}
$$

$\overline{\mathrm{C}_{22}}$ and $\overline{\mathrm{C}_{23}}$ can be approximated: $\overline{\mathrm{C}_{22}}=\overline{\sigma_{\mathrm{y}}} ; \overline{\mathrm{C}_{23}}=\overline{\sigma_{\mathrm{z}}}$

$\overline{\mathrm{C}_{33}}$ can be approximated by $\overline{\mathrm{C}_{33}}=\overline{\sigma_{\mathrm{z}}}$ when boundary conditions of $\varepsilon_{\mathrm{z}}=1$ and $\varepsilon_{\mathrm{x}}=\varepsilon_{\mathrm{y}}=$ $\gamma_{\mathrm{xy}}=\gamma_{\mathrm{yz}}=\gamma_{\mathrm{zx}}=0$ are applied: 


$$
\begin{aligned}
& x=0: u_{x}=0 ; \tau_{x y}=\tau_{z x}=0 ; \quad x=W x: u_{x}=0 ; \quad \tau_{x y}=\tau_{z x}=0 ; \\
& y=0: u_{y}=0 ; \tau_{x y}=\tau_{y z}=0 ; \quad y=F y: u_{y}=0 ; \quad \tau_{x y}=\tau_{y z}=0 ; \\
& z=0: u_{z}=0 ; \tau_{y z}=\tau_{z x}=0 ; \quad z=H z: u_{z}=H z ; \quad \tau_{y z}=\tau_{z x}=0 ;
\end{aligned}
$$

When boundary conditions of $\gamma_{\mathrm{xy}}=1$ and $\varepsilon_{\mathrm{x}}=\varepsilon_{\mathrm{y}}=\varepsilon_{\mathrm{z}}=\gamma_{\mathrm{yz}}=\gamma_{\mathrm{zx}}=0$ are applied:

$$
\begin{aligned}
& x=0: u_{y}=0 ; \sigma_{x}=\tau_{z x}=0 ; \quad x=W x: u_{y}=\frac{W x}{2} ; \quad \sigma_{x}=\tau_{z x}=0 ; \\
& y=0: u_{x}=0 ; \sigma_{y}=\tau_{y z}=0 ; \quad y=F y: u_{x}=\frac{F y}{2} ; \quad \sigma_{y}=\tau_{y z}=0 ; \\
& z=0: u_{z}=0 ; \tau_{y z}=\tau_{z x}=0 ; \quad z=H z: u_{z}=0 ; \quad \tau_{y z}=\tau_{z x}=0 ;
\end{aligned}
$$

$\overline{\mathrm{C}_{44}}$ can be approximated:

$$
\overline{\mathrm{C}_{44}}=\overline{\tau_{\mathrm{xy}}}=\frac{\int \tau_{\mathrm{xy}} \mathrm{dV}}{\mathrm{V}}
$$

When boundary conditions of $\gamma_{\mathrm{yz}}=1$ and $\varepsilon_{\mathrm{x}}=\varepsilon_{\mathrm{y}}=\varepsilon_{\mathrm{z}}=\gamma_{\mathrm{xy}}=\gamma_{\mathrm{zx}}=0$ are applied:

$$
\begin{aligned}
& x=0: u_{x}=0 ; \tau_{x y}=\tau_{z x}=0 ; \quad x=W x: u_{x}=0 ; \quad \tau_{x y}=\tau_{z x}=0 ; \\
& y=0: u_{z}=0 ; \sigma_{y}=\tau_{y z}=0 ; \quad y=F y: u_{z}=\frac{F y}{2} ; \quad \sigma_{y}=\tau_{y z}=0 ; \\
& z=0: u_{y}=0 ; \sigma_{z}=\tau_{z x}=0 ; \quad z=H z: u_{y}=\frac{H z}{2} ; \quad \sigma_{z}=\tau_{z x}=0 ;
\end{aligned}
$$

$\overline{\mathrm{C}_{55}}$ can be calculated:

$$
\overline{\mathrm{C}_{55}}=\overline{\tau_{\mathrm{yz}}}=\frac{\int \tau_{\mathrm{yz}} \mathrm{dV}}{\mathrm{V}}
$$

When boundary conditions of $\gamma_{\mathrm{zx}}=1$ and $\varepsilon_{\mathrm{x}}=\varepsilon_{\mathrm{y}}=\varepsilon_{\mathrm{z}}=\gamma_{\mathrm{xy}}=\gamma_{\mathrm{yz}}=0$ are applied:

$$
\begin{aligned}
& x=0: u_{z}=0 ; \sigma_{x}=\tau_{z x}=0 ; x=W x: u_{z}=\frac{W x}{2} ; \quad \sigma_{x}=\tau_{z x}=0 ; \\
& y=0: u_{y}=0 ; \tau_{x y}=\tau_{y z}=0 ; \quad y=F y: u_{y}=0 ; \quad \tau_{x y}=\tau_{y z}=0 ; \\
& z=0: u_{x}=0 ; \sigma_{z}=\tau_{z x}=0 ; \quad z=H z: u_{x}=\frac{H z}{2} ; \quad \sigma_{z}=\tau_{z x}=0 ;
\end{aligned}
$$

$\overline{\mathrm{C}_{66}}$ can be calculated:

$$
\overline{\mathrm{C}_{66}}=\overline{\tau_{\mathrm{zx}}}=\frac{\int \tau_{\mathrm{zx}} \mathrm{dV}}{\mathrm{V}}
$$

Note that although the effective shear moduli $\overline{\mathrm{C}_{44}}, \overline{\mathrm{C}_{55}}$ and $\overline{\mathrm{C}_{66}}$ obtained by applying similar set of boundary conditions $\left(\gamma_{\mathrm{yx}}=1, \gamma_{\mathrm{zy}}=1\right.$ and $\left.\gamma_{\mathrm{xz}}=1\right)$ should be identical, certain discrepancies between the two sets of results are due to inaccuracies and rounding errors in 
the computation. It was discussed in [11] that in such situation it is advisable to compute all six effective shear moduli from respective six sets of boundary conditions and calculate mean values for each of the three pairs. The FEM result of $\overline{\mathbf{C}}$ matrix for the straight-edge unit cell model, shown in Figure 4, calculated by equation (66) using results obtained by Bogdanovich [11], and the meshfree results obtained for the same unit cell model by different shape function constructions, Radial Basis(RB) and Moving Kriging(MK) respectively, are presented in Table 3.

Table 3 The homogenized elastic properties of the straight-edge unit cell model by different methods $(G P a)$

\begin{tabular}{cccccccccc}
\hline Method & $\mathbf{C}_{\mathbf{1 1}}$ & $\mathbf{C}_{\mathbf{1 2}}$ & $\mathbf{C}_{\mathbf{1 3}}$ & $\mathbf{C}_{\mathbf{2 2}}$ & $\mathbf{C}_{\mathbf{2 3}}$ & $\mathbf{C}_{\mathbf{3 3}}$ & $\mathbf{C}_{\mathbf{4 4}}$ & $\mathbf{C}_{55}$ & $\mathbf{C}_{\mathbf{6 6}}$ \\
\hline $\begin{array}{c}\text { FEM (applied strain) } \\
\text { [11] }\end{array}$ & 30.65 & 6.26 & 5.93 & 29.15 & 6.06 & 11.97 & 3.58 & 3.34 & 3.52 \\
$\begin{array}{c}\text { Meshfree method (RB) } \\
29.38\end{array}$ & 4.89 & 4.64 & 29.19 & 4.48 & 13.46 & 3.45 & 3.65 & 3.94 \\
Meshfree method (MK) & 30.08 & 5.02 & 4.79 & 29.88 & 4.66 & 13.79 & 3.58 & 3.84 & 4.06 \\
\hline
\end{tabular}

As it can be seen, Meshfree results are general in good agreement with the FEM [11] results. The relatively big differences of the coefficients like $\mathrm{C}_{33}$ are possibly due to, in Bogdanovich's work, specifically, the inclined Z-yarn elements in the straight-edge unit cell model are smeared with their surrounding matrix into homogeneous bricks for the sake of simplicity of its representation, because the straight-edge unit cell model still requires very fine discretization mesh due to the presence of inclined Z-yarn segments.

Meshfree methods are next applied to the smooth fabric unit cell model, which employs the same effective elastic properties as the straight-edge unit cell model (see Table 2). A comparison of the meshfree results of these two different unit cell models is given in Table 4 .

Table 4 The homogenized properties of the straight-edge unit cell model and the smooth fabric unit cell model by different meshfree methods (GPa)

\begin{tabular}{c|cccccccccc}
\hline Method & Approach & $\mathbf{C}_{\mathbf{1 1}}$ & $\mathbf{C}_{\mathbf{1 2}}$ & $\mathbf{C}_{\mathbf{1 3}}$ & $\mathbf{C}_{\mathbf{2 2}}$ & $\mathbf{C}_{\mathbf{2 3}}$ & $\mathbf{C}_{\mathbf{3 3}}$ & $\mathbf{C}_{\mathbf{4 4}}$ & $\mathbf{C}_{\mathbf{5 5}}$ & $\mathbf{C}_{\mathbf{6 6}}$ \\
\hline $\begin{array}{c}\text { Meshfree } \\
\text { method } \\
\text { (RB) }\end{array}$ & $\begin{array}{c}\text { Straight-edge } \\
\text { unit cell model }\end{array}$ & 29.38 & 4.89 & 4.64 & 29.19 & 4.48 & 13.46 & 3.45 & 3.65 & 3.94 \\
\hline $\begin{array}{c}\text { Smooth fabric } \\
\text { unit cell model }\end{array}$ & 29.72 & 5.11 & 4.93 & 27.12 & 4.84 & 13.17 & 3.45 & 4.07 & 3.71 \\
\hline $\begin{array}{c}\text { Meshfree } \\
\text { method } \\
\text { (MK) }\end{array}$ & $\begin{array}{c}\text { Straight-edge } \\
\text { unit cell model }\end{array}$ & 30.08 & 5.02 & 4.79 & 29.88 & 4.66 & 13.79 & 3.58 & 3.84 & 4.06 \\
\hline $\begin{array}{c}\text { Smooth fabric } \\
\text { unit cell model }\end{array}$ & 26.66 & 4.59 & 4.41 & 24.32 & 4.33 & 12.01 & 3.11 & 3.66 & 3.35 \\
\hline
\end{tabular}

It is notable that two different shape function constructions, RB and MK, give different changes between the results of two unit cell models. Therefore, looking into the convergence of these two meshfree methods is essential. The results of $\mathrm{C}_{11}, \mathrm{C}_{22}$ and $\mathrm{C}_{33}$ are analyzed to show the effect of changing the size of sub-domains, as shown in Figure 10 (a) and (b). The parameter mn stands for the minimum number of support nodes inside sub-domains. In Figure 
10 (a), the results of the straight-edge unit cell model are shown and the first columns are the FEM results. Figure 10 (b) presents the convergence obtained by smooth fabric unit cell model. The highlighted columns are the results listed in Table 3, 4 and 5.

It can be seen that by increasing the sizes of sub-domains, meshfree methods using RB function and MK interpolation show different convergence. Although the results obtained by RB function are in better agreements with FE results while mn chosen to be 12 in this case, MK interpolation as shape function construction in general gives more stable results.

Moreover, for meshfree methods based on RB function and MK interpolation, different nodal distributions are also applied respectively to show the convergence. Figure 11 shows the results of $\mathrm{C}_{11}, \mathrm{C}_{22}$ and $\mathrm{C}_{33}$ by applying these two different shape functions on both straightedge and smooth fabric unit cell models with different evenly distributed nodes, from $5 * 5 * 3$ to $12 * 12 * 10$.

The minimum amount of support nodes in sub-domains, mn, was set to be 12 , while different nodal distributions were analyzed. The highlighted columns are the results listed in Table 3, 4 and 5. As it can be seen, again, Moving kriging interpolation leads to better convergence comparing with using Radial basis function in this case.
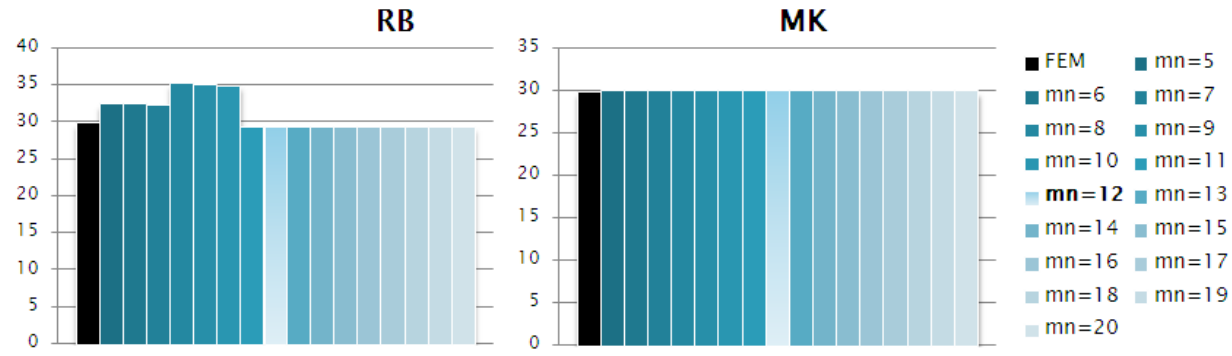

Cl1
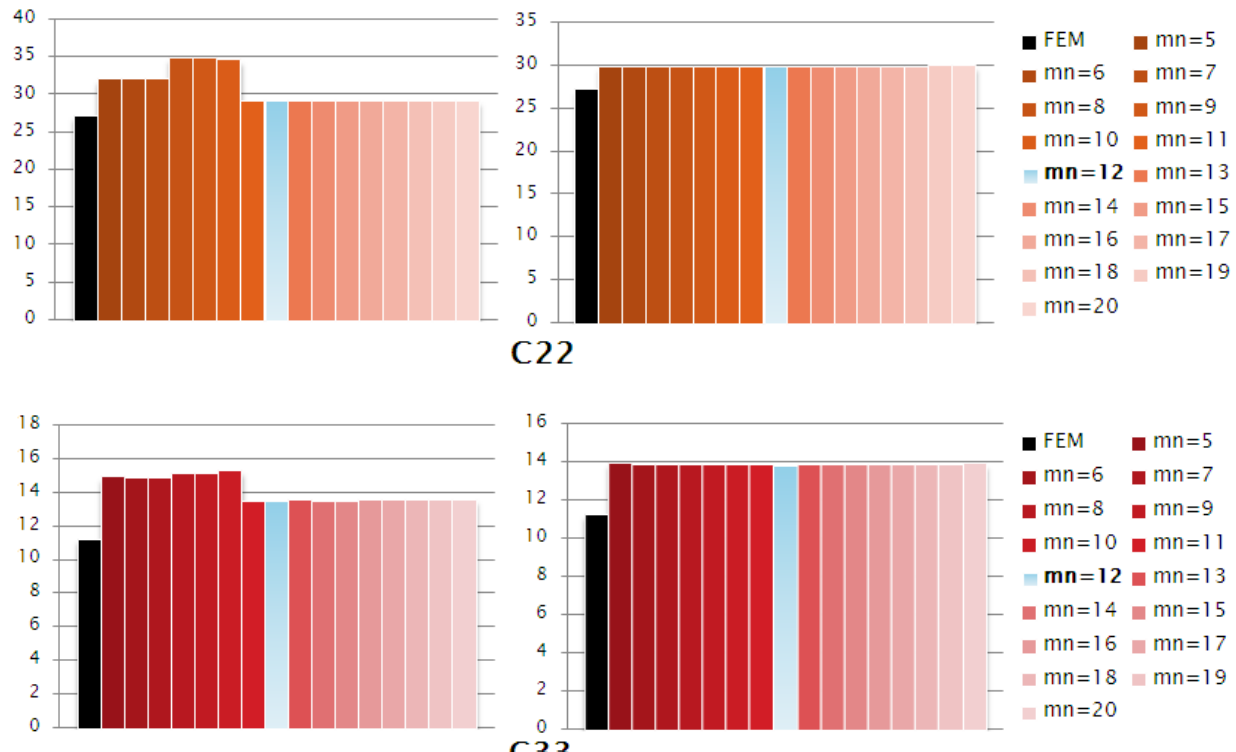

(a) 

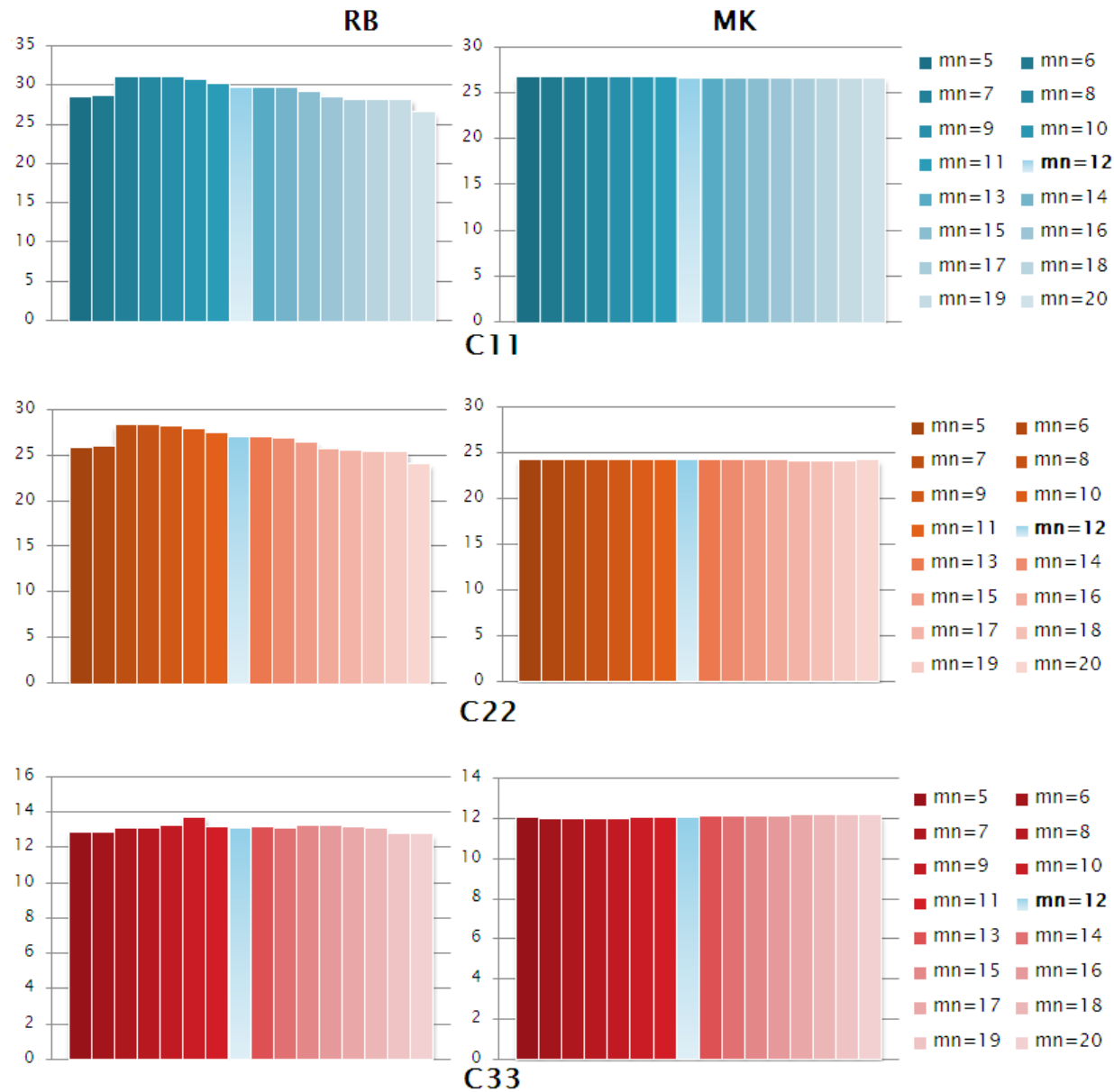

(b)

Figure 10 Results C11, C22 and C33 (GPa) of (a) straight-edge unit cell and (b) smooth fabric unit cell model obtained by enlarging the sub-domains under $11 * 11 * 9$ nodal distribution (mn stands for the minimum number of support nodes inside sub-domains)
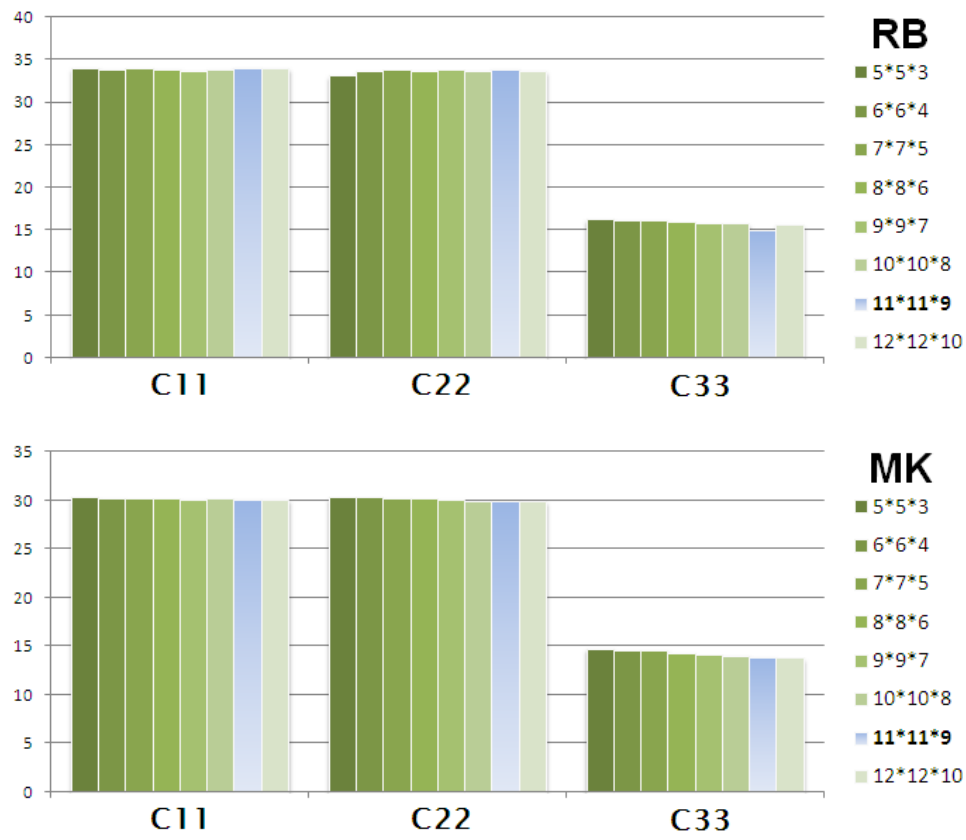

(a) 

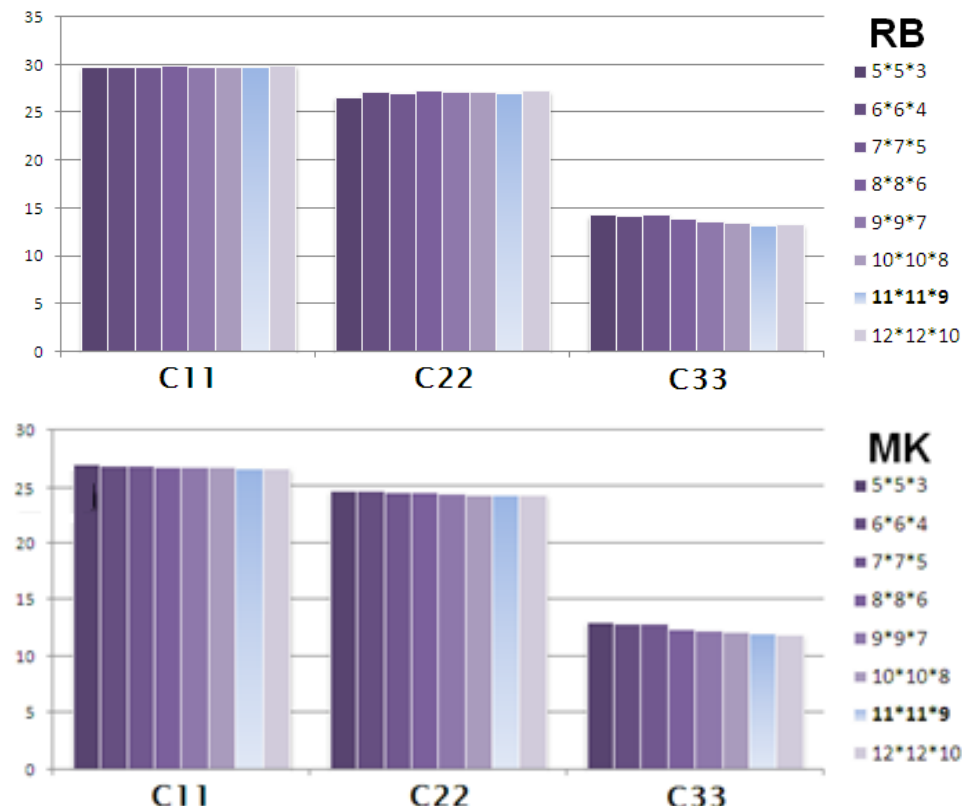

(b)

Figure 11 Results C11, C22 and C33 (GPa) of (a) straight-edge unit cell and

(b) smooth fabric unit cell model obtained by increasing the amount of evenly distributed nodes with mn (minimum number of support nodes inside sub-domains) $=12$

Table 5 Comparison of $3 D$ orthogonal woven composites elastic moduli obtained by different numerical approaches with the experimental results

\begin{tabular}{|c|c|c|c|c|c|c|c|c|c|c|}
\hline Approach & Method & $\begin{array}{c}\mathbf{E}_{1} \\
\mathbf{G P a}\end{array}$ & $\begin{array}{c}\mathbf{E}_{2} \\
\mathbf{G P a}\end{array}$ & $\begin{array}{c}\mathbf{E}_{\mathbf{3}} \\
\mathbf{G P a}\end{array}$ & $\begin{array}{r}\mathbf{G}_{12} \\
\mathbf{G P a}\end{array}$ & $\begin{array}{r}\mathbf{G}_{13} \\
\mathbf{G P a}\end{array}$ & $\begin{array}{r}\mathbf{G}_{23} \\
\mathbf{G P a}\end{array}$ & $\mathbf{v}_{12}$ & $\mathbf{v}_{13}$ & $\mathbf{v}_{23}$ \\
\hline \multirow{3}{*}{$\begin{array}{l}\text { Straight-edge } \\
\text { unit cell model }\end{array}$} & $\begin{array}{c}\text { FEM } \\
\text { (applied } \\
\text { strain) } \\
{[11]}\end{array}$ & 27.31 & 25.70 & 9.98 & 3.58 & 3.52 & 3.34 & 0.125 & 0.432 & 0.448 \\
\hline & $\begin{array}{l}\text { Meshfree } \\
\text { method } \\
(\mathrm{RB})\end{array}$ & 27.37 & 27.29 & 12.24 & 3.45 & 3.94 & 3.65 & 0.121 & 0.291 & 0.305 \\
\hline & $\begin{array}{c}\text { Meshfree } \\
\text { method } \\
(\mathrm{MK})\end{array}$ & 28.01 & 27.90 & 12.51 & 3.58 & 4.06 & 3.84 & 0.120 & 0.296 & 0.307 \\
\hline \multirow{2}{*}{$\begin{array}{l}\text { Smooth fabric } \\
\text { unit cell model }\end{array}$} & $\begin{array}{c}\text { Meshfree } \\
\text { method } \\
(\mathrm{RB})\end{array}$ & 27.45 & 24.95 & 11.74 & 3.45 & 3.71 & 4.07 & 0.130 & 0.323 & 0.327 \\
\hline & $\begin{array}{c}\text { Meshfree } \\
\text { method } \\
(\mathrm{MK})\end{array}$ & 24.61 & 22.38 & 10.78 & 3.11 & 3.37 & 3.69 & 0.132 & 0.316 & 0.319 \\
\hline \multicolumn{2}{|c|}{$\begin{array}{c}\text { Experimental (tension) } \\
{[11]}\end{array}$} & 24.68 & 20.75 & N/A & & & & 0.11 & N/A & N/A \\
\hline
\end{tabular}


By using Equation (66), the elastic moduli of 3D orthogonal woven composites can be obtained easily. The results of two different unit cell models, straight-edge and smooth fabric model, obtained by employing different methods, FEM [11] and meshfree methods, which use Radial Basis functions and Moving Kriging interpolations as shape function construction respectively are concluded in Table 5. The numerical results are compared with the experimental results of the fabricated composites, which is $93 \mathrm{oz} 3 \mathrm{D}$ woven S-2 Glass/Dow Derakane 8084 Epoxy-Vinyl Ester resin composites. It can be seen that smooth fabric unit cell model gives closer results to the experimental results while applying MK interpolation as the meshfree shape function construction. It is also worth noting that the CPU time for running the evaluation by using meshfree methods, from generating the geometry of the unit cell model to calculating out the homogenized elastic properties, is only approximately 20 minutes in this case, while FEM would take hours generating the mesh.

\section{Conclusion}

A new unit cell model of 3D orthogonal woven fabric composites, with a more realistic yarn representation, was developed and implemented into meshfree method to evaluate the elastic moduli of 3D orthogonal woven composites. The distribution of the fibres in the model can be arbitrary and the geometry of the model can be curved surfaces while the prediction of micromechanical properties can be easily obtained by meshfree method. Two different shape function constructions, Radial Basis function and Moving Kriging interpolation, were applied in the meshfree method respectively. The meshfree numerical results obtained from the same unit cell model as Finite Element approach were found to be in good agreement with finite element solutions. While employing meshfree methods to both straight-edge and smooth fabric unit cell models, the convergences of using Moving Kriging interpolation were shown to be better. The numerical results obtained from the smooth fabric model were found to be closer to the experimental results comparing with the straight-edge unit cell model by MK approach. A notable advantage of the proposed method is the simplicity of the mesh which leads to a much shorter total CPU time, including the time for generating geometry, adding boundary conditions, solving system equations, etc.

\section{References}

1. T. Ishikawa and T. W. Chou, Stiffness and strength behaviour of fabric composites, J. Mater. Sci., 17, 3211-3220, 1982

2. N. K. Naik and P. S. Shembekar, Elastic behaviour of woven fabric composites: I-lamina analysis, J. Compos. Mater., 26, 2196-2225, 1992

3. M. Karayaka and P. Kurath, Defomation and failure behaviour of woven composite laminates, $J$. Eng. Mater. Technol., 116, 222-232, 1994

4. A. Tabiei and Y. Jiang, Woven fabric composite material model with material non-linearity for nonlinear finite element simulation, Int. J. Solids and Struct., 36, 2757-2771, 1999

5. R. Tanov and A. Tabiei, Computationally efficient micromechanical models for woven fabric composite elstic moduli, J. Appl. Mech., 68, 553-560, 2001

6. James Lua, Thermal-mechanical cell model for unbalanced plain weave woven fabric composites, Composites Part A: Applied Science and Manufacturing, 38(3), 1019-1037, 2007

7. P. H. Wen and M. H. Aliabadi, Mesh-free micromechanical model for woven fabric composite elastic moduli, Journal of Multiscale Modelling, 1, No. 2, 303-319, 2009

8. P. Tan, LY. Tong, GP. Steven, Models approaches for orthogonal woven composites, J Reinforced Plast Compos, 17(6), 545-77, 1998

9. Zuorong Chen, Shouwen Yu, Xiqiao Feng, Lu Meng, and Ye Lin, Evaluation of thermo-elastic properties of three dimensional orthogonal woven composites, Composites: Part B, 33, 241-251, 2002 
10. Chang Sung Lee, Soon Wan Chung, Heon Shin, and Seung Jo Kim, Virtual material characterization of 3D orthogonal woven composite materials by large-scale computing, Journal of Composite Material, 39, No.10, 2005

11. A. E. Bogdanovich, Multi-scale modelling, stress and failure analyses of 3-D woven composites, $J$ Mater Sci, 41, 6547-6590, 2006

12. R. V. Marrey and B. V. Sankar, A micromechanical model for textile composite plate, J. Compos. Mater., 31, 1187-1213, 1977

13. P. W. Chung and K. K. Tamma, Woven fabric composites - Developments in engineering bounds, homogenization and application, Int. J. Numer. Meth. Eng., 45, 1757-1790, 1999

14. P. Potluri and V. S. Thammandra, Influence of uniaxial and biaxial tension on meso-scale geometry and strain fields in a woven composites, Compos. Struct., 77, 405-418, 2007

15. J. Schuster, D. Heider, K. Sharp, and M. Glowania, Measuring and modelling the thermal conductivities of three-dimensionally woven fabric composites, Mechanics of Composite Materials, 45, No.2, 2009

16. N. D. Ngo and K. K. Tamma, Complex three-dimensional microstructural permeability prediction of porous fibrous media with and without compaction, Int. J. Numer. Meth. Engineering, 60, 17411757,2004

17. L. Dickinson, M. Mohamed, A. Bogdanovich, 3-D weave: what, how and where, 44th International SAMPE Symposium and Exhibition, 1, 303-312, 1999

18. R. A. Gingold, and J. J. Monaghan, Smooth particle hydrodynamics: theory and applications to non-spherical stars, Mon. Not. R. Astron. Soc., 181, 375-389, 1977

19. E. Onate, et. Al., A finite point method in computational mechanics applications to convective transport and fluid flow, Int. J. Numer. Meth. Eng., 39, 3839-3866, 1996

20. B. Nayroles, G. Touzot, and P. Villon, Generalizing the finite element method: diffuse approximation and diffuse elements, Comput. Mech., 10, 307-318, 1992

21. T. Belytschko, Y. Y. Lu, and L. Gu, Element-Free Galerkin Methods, Int. J. Numer. Meth. Engineering, 37, 229-256, 1994

22. W. K. Liu, S. Jun, and Y. Zhang, Reproducing kernel particle methods, Int. J. Numer. Meth. Fluids, 20, 1081-1106, 1995

23. C. A. Duarte, and J. T. Oden, An hp adaptive method using clouds, Compt. Meth. Appl. Mech. Eng., 139, 237-262, 1996

24. G. Yagawa, and T. Yamada, Free mesh method, a kind of meshless finite element method, Comput. Mech., 18, 383-386, 1996

25.S. N. Atluri, and T. Zhu, A new meshless local Petrov-Galerkin (MLPG) approach in computational mechanics, Comput. Mech., 22, 117-127, 1998

26. G. R. Liu, and Y. T. Gu, A point interpolation method, in Proc. $4^{\text {th }}$ Asia-Pacific Conference on Computational Mechanics, 1009-1014, 1999

27. P. H. Wen, and M. H. Aliabadi, Meshless method with enriched radial basis functions for fracture mechanics, SDHM, 3(2), 107-119, 2007

28. P. H. Wen, and M. H. Aliabadi, Applications of meshless method to fracture mechanics, Proc. Boundary Element Technique 2007, Naples, Italy, pp., 135-145, 2007

29. P. H. Wen, M. H. Aliabadi, An improved meshless collocation method for elastostatic and elastodynamic problems, Commun. Numer. Meth. Eng., 24, 635-651, 2008

30. P. H. Wen, M. H. Aliabadi, and Y. W. Liu, Meshless method for crack analysis in functionally graded materials with enriched radial basis functions, CMES, 30(3), 133-147, 2008

31. Lei Gu, Moving kriging interpolation and element-free Galerkin method, Int. J. Numer. Meth. Engng, 56, 1-11, 2003

32. R. L. Hardy, Multiquadric equations of topography and other irregular surfaces, journal of Geophysical Research, 76(8), 1905-1915, 1971

33. G. Matheron, principles of geostatistics, Economic Geology, 58, 1246-1266, 1963

34. J. Sacks J, W. J. Welch, T. J. Mitchell, and H. P. Wynn, Design and analysis of computer experiments, Statistical Science, 4, 409-435, 1989 
35. P. Lancaster, K. Salkauskas, Surface generated by moving least square methods, Mathematics of Computation, 37, 141-158, 1981

36. A. E. Bogdanovich, Proceedings of $35^{\text {th }}$ international SAMPE technical conference, vol 35, Dayton OH, Sept 28 - Oct 2, 2003 